\title{
An experimental data-set on merging flows in rail tunnel evacuation
}

\author{
Arturo Cuesta (cuestaar@unican.es); Orlando Abreu (abreu@unican.es); Adriana Balboa \\ (balboaa@unican.es) and Daniel Alvear (alveard@unican.es \\ GIDAI Group - Fire Safety- Research and Technology, University of Cantabria \\ Ave. Los Castros, s/n. 39005 Santander. (Spain) \\ Tel.: +34 942201826 Fax: +34 942201873
}

\begin{abstract}
The main purpose of this study was to investigate the impact of merging conditions during evacuation process in rail tunnels. The experiment was carried out in a mock-up of a rail car with a single exit towards a lateral corridor. Eight exit configurations were tested involving 77 participants with a reasonable proportion of ageing subjects (age mean 48; standard deviation 15; range 18-74). New measurements and data processing methods were proposed and used. Observations from video recordings complemented the quantitative analysis revealing behavioural patterns of participants. As confirmed by results, the occurrence of merging had a negative effect during evacuation. The rail car exit flow and the walkway flow decreased when merge. The relationship between both flows varied considerably during the merging period. However, we found that the higher the height differential of the rail car exit the more dominance of the walkway flow. The bias in the evacuation was slightly in favour of the walkway when there was not height differential of the rail car exit. Contrary to expectations, we found a moderate dominance of walkway flow with a height differential of the rail car exit of $0.8 \mathrm{~m}$. However, there was a clear dominance of the walkway flow over the rail car exit flow when the rail car exit was $1.2 \mathrm{~m}$ in height. We also found no gender playing a role in deference behaviour (male helping female).
\end{abstract}

Keywords: Rail tunnel evacuation, merging flows, experimental data-set, deference behaviour

\section{Introduction}

Safety of rail passengers is such a relevant research issue for emergency response planners, safety managers, transport engineers, rail operators and policy makers. One of the main concerns of rail safety is that high capacity trains operate in tunnels and underground spaces. As long as "hot" incidents occur inside the tunnel (fire, explosion followed by fire, emission of toxic smoke or gasses), the priority is to reach an external place for the evacuation (i.e. the closest station). However, this is not always possible and passengers may be required to leave the train and then evacuate the tunnel (e.g. by a cross passage or the tunnel portal) away from the threat as fast as possible. This is bound to be problematic since train exit flows and walkway flow are likely to be constrained due to merging conditions, increasing the required time for evacuees to reach a safe place (Fridolf et al. 2014a). In such conditions, an appropriate design and an effective evacuation strategy can save lives (Alvear et al. 2013). As far as rail tunnel design concerned, national guidelines, regulations and standards provide parameters to get a safety evacuation. Although on the whole, there is a lack of homogeneity in evacuation design requirements. In addition, many accident reports have described a lack of training and preparedness in emergency procedures (Train door Emergency Egress, 2004). To address this, rail companies, authorities and stakeholders usually perform full-scale drills. These tests have various problems, such as their lack of realism and their economic cost. Furthermore, it is well known that single trials produce limited information of the variety of potential outcomes seen in evacuation processes.

On the other hand, computer modelling analysis has advantages such as the reduction of the actual trials and the increase of the number of scenarios in the analysis. Simulation models can provide consistent and accurate results when reliable inputs are used (Capote et al., 2012a; 2012b). While 
the potential of such approach is clear (Cuesta et al., 2014; 2016; Wang and Lo, 2014; Weyenberge and Deckers, 2014), computer modelling analyses are not always supported by empirical data, since there is a slight availability of sufficiently detailed, comprehensive and relevant data for supporting design requirements and/or computer modelling analyses. There are a limited number of data-sets in the literature describing the performances of evacuees in rail tunnels including train exit flow rates (Fridolf et al., 2014a; 2016; Marlos and Pollar, 2013: Kim et al., 2012; Oswald et al., 2008; 2011; Nórén and Winér, 2003), walking speeds in smoky conditions (Seike, et al., 2016; Fridolf et al., 2014b; Frantzich and Nilsson, 2004), walking speeds on a tunnel walkway (Lundstrom et al., 2014) and exit strategies to overcome the height of train exits (Oswald et al., 2008). Moreover, even though many authors have reported distinct issues regarding safety in rail tunnels, there has been little research on evacuation. The purpose of the present study is therefore to analyze the potential impact of merging conditions during evacuation in rail tunnels by collecting empirical data that are analysed using mathematically based methods, in particular statistics. The paper is organized as follows. Section 2 briefly discusses the relevant empirical studies on pedestrian dynamics on merging configurations. While Section 3 describes the controlled laboratory experiments for different train exit configurations and the measurement methods used, Section 4 presents results mainly focused on the reciprocal influence of the merging flows and the behaviour of participants. Finally, Section 5 discusses related work and concludes the paper with some indications for future work.

\section{Empirical studies on pedestrian merging configurations}

Nowadays, there are a limited number of empirical studies which have specifically investigated pedestrian merging flows. These studies can be divided into 1) staircase merging studies and 2) horizontal merging studies.

On the one hand, the former studies are focused on the way in which people from the stair and the floor merge in the stair landings during evacuation. Data are often collected with different methods, background conditions (controlled experiments and evacuation drills), stair configurations and considering different behavioural factors. This leads to disagreements on the findings (Sano et al, 2017). For instance, in (Pauls, 2004) it was claimed that people already in the stair allowed people entering the stair from lower floors to proceed first in congested situations whereas other studies claimed an approximate merging ratio of 50:50 (Hukugo et al., 1985; Boyce et al., 2012; Sano et al., 2015). Some other research works paid attention to the stair configuration (i.e the position of the door in the landing) and its impact on the evacuation time of a floor (Boyce et al., 2012; Melly et al., 2009; Takeichi et al., 2005). The use of simulation tools could provide insights into this aspect (Galea, et al. 2008; Hamacher, et al. 2011).

On the other hand, horizontal merging studies have been traditionally conducted on a single rightangle merging setup (also referred as T-junction). Although several measurement methods have been applied to the study of merging in corridors (Zhang et al., 2011; Craesmeyer et al., 2014) the Voronoi method was found to be the most used (Boltes et al., 2011; Zhang et al., 2011; Zhang et al., 2013) as it is able to resolve the fine structure of the fundamental diagram (Zhang et al., 2011). One finding was that fundamental diagrams of a T-junction flow were different before and after merging because merging process led to a flow restriction (Boltes et al., 2011). Furthermore, the study of (Zhang et al., 2011) showed that fundamental diagrams from different facilities (Tjunction vs straight corridor) were not comparable. When the outflow and the inflow were not equal, a transition between low and high densities appeared in the pedestrian flow. Recent empirical researches explored additional configurations to assess the impact of different merging angles. These studies demonstrated that the merging angle and flow direction had impact on the overall outflow. For instance, one of the main findings was that the higher the merging angle the lower the pedestrian flow (Shiwatoki et al., 2015; Shi et al., 2016). Other finding was that the visual access was likely to produce better throughput than a blocked view of pedestrians while merging (Aghabayk et al., 2014). 
To sum up, while considerable research has been devoted to merging flows, no research has looked into merging during evacuation in rail tunnels. There is a need to determine the cause and effect relationship between the population inside the tunnel and the flow rate capacity of a train exit, as this is expected to have a significant influence on the total evacuation time (Fridolf et al. 2014a). Therefore, the primary objective of our paper is to provide how merging behaviour affects in a right-angle configuration that represents the train exit (with "height differential") and the lateral walkway inside a rail tunnel, providing data collection, processing methods and the datasets for further research so as to better understand the merging process and the impact of interactions among passengers during evacuation.

\section{Experiment set up}

Field experiments in a real-world setting require significant economic cost and organization effort (e.g. a train inside a rail tunnel). Since this study was focused on a primary performance factor, we conducted laboratory experiments at the University of Cantabria (Spain) on the 13th of August 2014. The experiment was carried out in a mock-up of a rail car with a single exit towards a lateral corridor. Different geometry configurations were used to study merging flows. In this section the layout, participants, scenarios, experiment procedure and measurement methods are described.

\subsection{Layout}

Figure 1 shows the experiment setup. The mock-up of the rail car (made of wood) consisted of two ramps leading access to a vestibule adjustable at different heights $(0.20,0.40,0.60,0.80,1.00$ and $1.20 \mathrm{~m})$. The vestibule had an exit with a sliding door able to adjust to different widths $(0.80$ and $1.20 \mathrm{~m}$ ). The walking corridor ( $12 \mathrm{~m}$ in length) was attached to the rail car model to meet the right-angle configuration. The boundary material of the walking corridor was opaque canvas (3 $\mathrm{m}$ in height) solid enough to represent the walls (e.g. blocked vision conditions to participants). Note that the width of the walking corridor could be modified as well. In other words, the experiment setup was flexible enough to easy manipulate the geometry and explore different exit configurations (see Fig. 2).

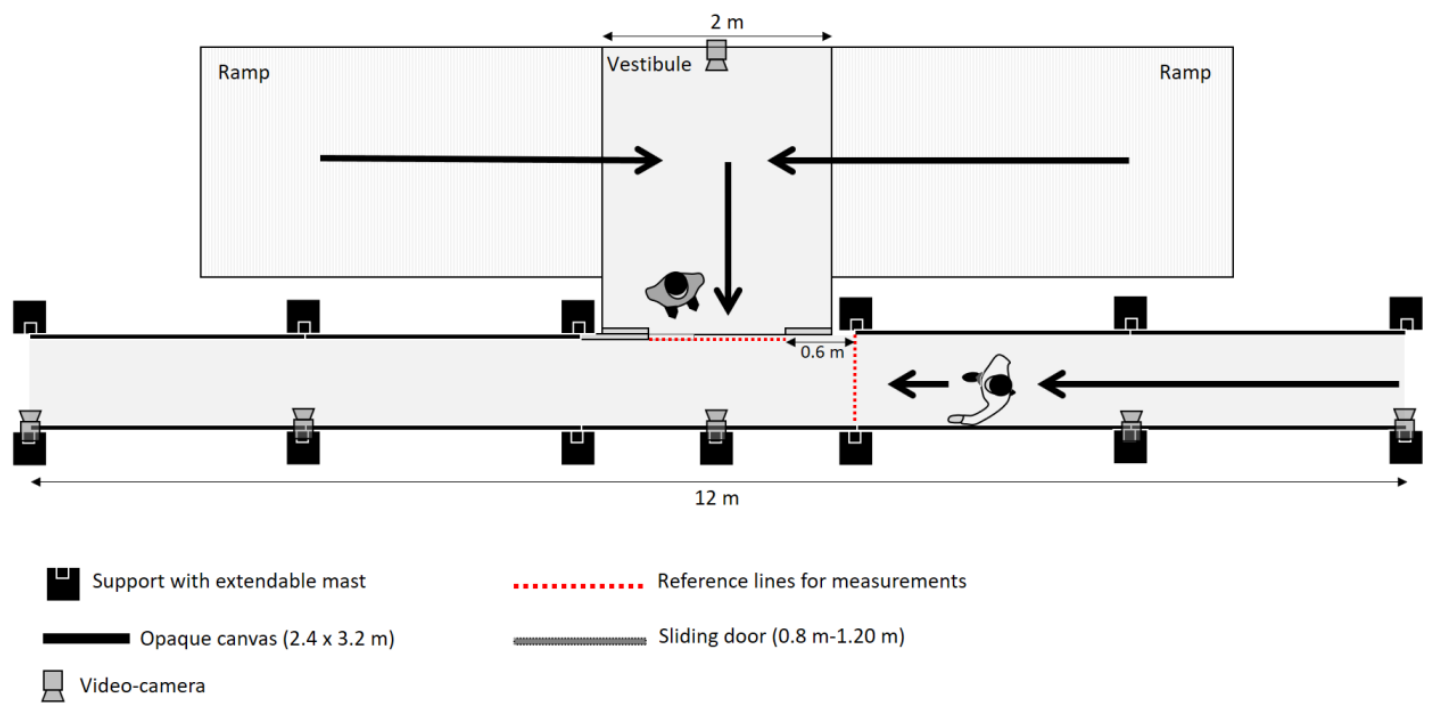

Fig. 1. Experiment setup. 


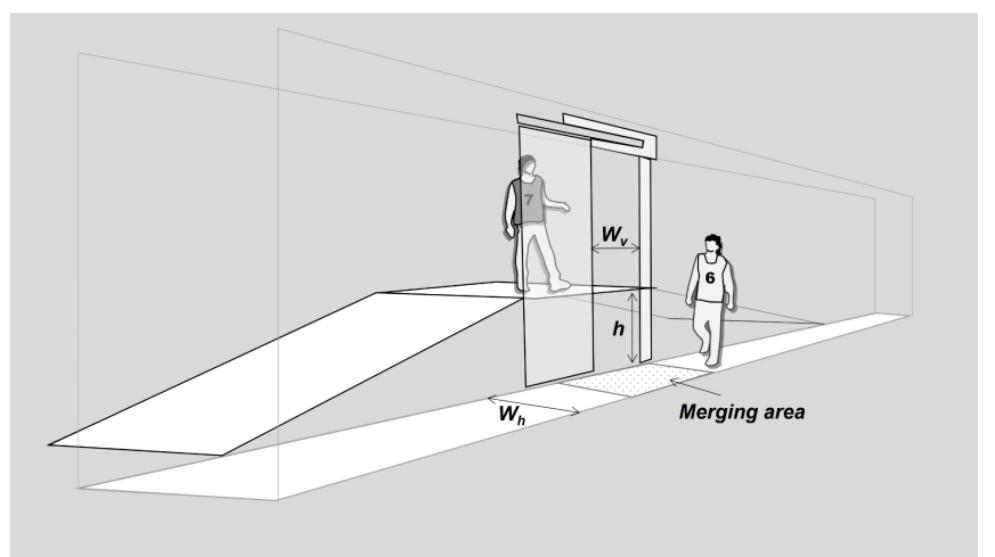

Fig. 2. Independent variables manipulated for testing different exit configurations:1) $W_{v}=$ the width of the train exit, 2) $W_{h}=$ the width of the lateral walkway and 3) $h=$ the height differential of the train exit.

\subsection{Participants}

A deliberate effort was made to recruit a reasonable proportion of ageing subjects to test a sample representative of future rail transport users. Demographic information derived from Eurostat population projections ${ }^{1}$ was used as a reference to recruit the participants. The population demographics are shown in Figure 3. In total 77 participants took part in experiment, 37 women (48\%) and 40 men (52\%). The age of participants varied from 18 to 74 years, with an average of 48 years and a standard deviation 15 years. Due to ethical reasons, no children were used. Participants were volunteers recruited by a company and covered with casualty insurance. They received information and signed an informed consent form beforehand the experiments. As reward, participants were given a raffle ticket for a laptop, a dinner and a spa for two persons. Since the experiments were performed in summer, the participants did not wear jackets, jumpers, coats, etc. However, by $21 \%$ of participants carried backpacks and by $62 \%$ of female participants had their handbags with them during the experiment.

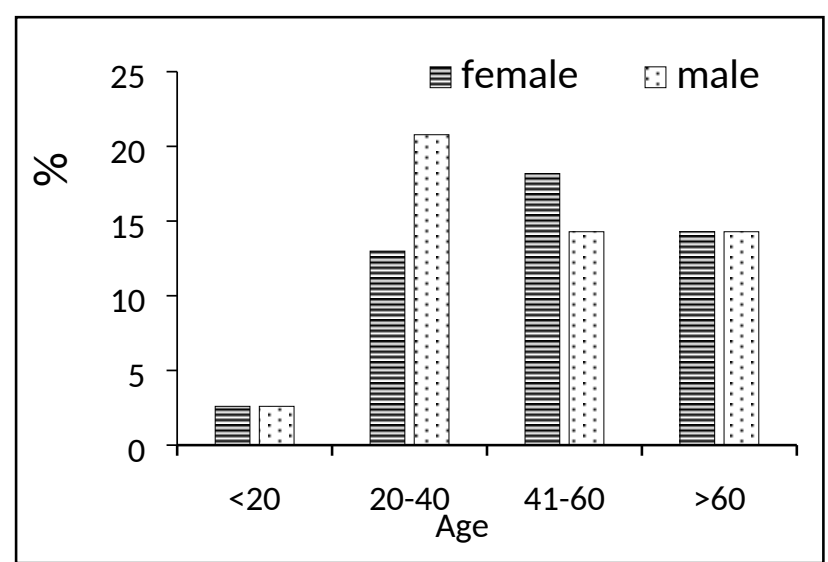

Fig. 3. Age and gender of participants.

\subsection{Experiment procedure}

Table 1 displays the basic information of the tests conducted. The height differential $(h)$ and the width of the train exits $\left(W_{v}\right)$ were based on high speed trains and regional trainsets which operate in Spain. Similarly, the walkway widths $\left(W_{h}\right)$ were taken from (European Commission, 2014). The flexibility of the mock-up allowed us to arrange different exit configurations. In total 16 tests were conducted considering eight exit configurations (see Table 1).

\footnotetext{
${ }^{1}$ Eurostat population projections: http://ec.europa.eu/eurostat/statisticsexplained/index.php/People in the EU \%E2\%80\%93 population projections
} 
The alphabetical order of participant surnames was used as a random sampling method to form the two experimental groups, namely Red group (39 participants) and Yellow group (38 participants). Each participant wore a coloured vest (red or yellow) with a number to be identified during experiment. Two tests were carried out for each exit configuration switching the starting location of the groups (see Table 1). One group was located on the mock-up of the rail car and another group formed a queue to access the walkway (see Figure 3). When both groups were at their respective positions, a whistle signal was used to initiate the movement of participants. The test finished when all participants left the walkway. Then, participants were asked to go to another starting position for the next test (i.e. those who started from the walkway were asked to go to the rail car and vice versa). We took care to ensure that the position of the individuals within the group was randomly located (e.g. participants who were at front/back in one test in the walkway or in the rail car were randomly located to middle/front in next test). This was intended to minimise the cumulative learning behaviour of participants by introducing the randomness in their location. There were breaks every two tests to modify the rail car exit configurations (see Table 2). Therefore, participants had enough time to rest. Given this, learning and fatigue did not appear to be significant factors in any of the tests conducted. During the breaks participants were asked to take part in next tests. Some participants refused to take part in some tests as they felt unable to overcome height differentials of the rail car exit $(0.8 \mathrm{~m}$ and $1.2 \mathrm{~m})$. This is discussed in section 4.4 of this paper.

\begin{tabular}{|c|c|c|c|c|c|}
\hline \multirow{2}{*}{ Test } & \multicolumn{2}{|c|}{ Starting location of groups } & \multicolumn{3}{c|}{ Independent variables (exit configuration) } \\
\cline { 2 - 6 } & $\begin{array}{c}\boldsymbol{R} \text { Red } \\
\text { (\#participants) }\end{array}$ & $\begin{array}{c}\text { Yellow } \\
\text { (\#participants) }\end{array}$ & $\boldsymbol{W}_{\boldsymbol{h}}(\mathbf{m})$ & $\boldsymbol{W}_{\boldsymbol{v}}(\mathbf{m})$ & $\boldsymbol{h}(\mathbf{m})$ \\
\hline 1 & Rail car & Walkway & 1.2 & 0.8 & 0 \\
\hline 2 & Walkway & Rail car & 1.2 & 0.8 & 0 \\
\hline 3 & Rail car & Walkway & 1.2 & 1.2 & 0 \\
\hline 4 & Walkway & Rail car & 1.2 & 1.2 & 0 \\
\hline 5 & Walkway & Rail car & 0.8 & 0.8 & 0 \\
\hline 6 & Rail car & Walkway & 0.8 & 0.8 & 0 \\
\hline 7 & Walkway & Rail car & 0.8 & 1.2 & 0 \\
\hline 8 & Rail car & Walkway & 0.8 & 1.2 & 0 \\
\hline 9 & Rail car & Walkway & 0.8 & 0.8 & 0.8 \\
\hline 10 & Walkway & Rail car & 0.8 & 0.8 & 0.8 \\
\hline 11 & Rail car & Walkway & 1.2 & 0.8 & 0.8 \\
\hline 12 & Walkway & Rail car & 1.2 & 0.8 & 0.8 \\
\hline 13 & Walkway & Rail car & 1.2 & 1.2 & 1.2 \\
\hline 14 & Rail car & Walkway & 1.2 & 1.2 & 1.2 \\
\hline 15 & Walkway & Rail car & 0.8 & 1.2 & 1.2 \\
\hline 16 & Rail car & Walkway & 0.8 & 1.2 & 1.2 \\
\hline
\end{tabular}

Table 1. Tests conducted and values of the manipulated independent variables.

\begin{tabular}{|c|l|c|}
\hline Break & \multicolumn{1}{|c|}{ Description } & Time (min:s) \\
\hline 1 & After Test 2 to change the width of the rail car exit & $4: 32$ \\
\hline 2 & After Test 4 to change the widths of the rail car exit and the walkway & $22: 37$ \\
\hline 3 & After Test 6 to change the width of the rail car exit & $2: 31$ \\
\hline 4 & $\begin{array}{l}\text { After Test 8 to change the width and height of the rail car exit and } \\
\text { ask participants if they were willing to take part in the next test }\end{array}$ & $32: 30$ \\
\hline 5 & $\begin{array}{l}\text { After Test 10 to change width of the walkway and ask participants } \\
\text { if they were willing to participate }\end{array}$ & $13: 24$ \\
\hline 6 & $\begin{array}{l}\text { After test 12 to change the width and height of the rail car exit and } \\
\text { ask participants if they were willing to take part in the next test }\end{array}$ & $36: 30$ \\
\hline 7 & $\begin{array}{l}\text { After Test 14 to change the walkway width ask participants if they } \\
\text { were willing to take part in the next test }\end{array}$ & $13: 18$ \\
\hline
\end{tabular}

Table 2. Breaks during the experiment. 


\subsection{Measurement methods}

For the data collection 6 video-cameras were placed to obtain an overhead view of the rail car exit and the walkway. But only recordings from one video-camera were used for the data collection presented here. Video images were collected at a frequency of 29.97 frames/s. Video recordings were analysed manually frame by frame using the Avidemux 2.5.2 software. Two reference lines were previously defined to measure the merging flows (see Figure 1). The first reference line was the rail car exit and the second reference line was marked on the floor of the walkway $0.6 \mathrm{~m}$ before the rail car exit (see Figure 1). The merge area was a square/rectangle based on these reference lines. As Figure 4 shows, the software allows selecting/excluding regions to avoid "noise" in the manual measurements. The frame when all parts of individual's bodies had crossed the reference lines was noted and then transcribed into a spreadsheet.

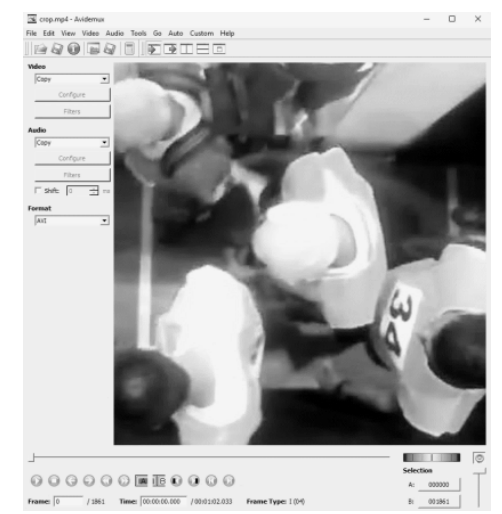

Fig.4. Specific region used for data processing.

To date various methods have been developed and introduced to measure the flow rates of evacuating persons. However, the use of a simple flow rate to represent exit performance tends to average personal hesitations and limitations in exiting performance, producing a simple representation of the actual passenger rail car exit flow (Galea et al. 2014). Although most of building evacuation models do not use stochastic variables to implement the flows, current rail car evacuation models consider exit time probability distributions rather than simple flow rates (Capote et al. 2012b; Galea et al. 2014). That is why the measurements were made according to the definition of a new random variable, namely the instantaneous specific flow $\left(\hat{F}_{s}\right)$ defined as the inverse of the time interval between two subjects that consecutively cross a point of reference $\left(\Delta t_{i, i-1}\right)$, divided by the effective width $\left(w_{e f}\right)$.

$$
\hat{F}_{S}=\frac{1}{\Delta t_{i, i-1} \cdot w_{e f}}
$$

As the specific flow $\left(F_{s}\right)$, the instantaneous specific flow $\left(\hat{F}_{s}\right)$ is the flow of evacuating persons past a point per unit of time per unit of effective width (Gwynne and Rosenbaum, 2015). Equation (1) shows how to measure the flow of evacuating persons without using the original expression $F_{s}$ $=S D$ where $S$ is the speed of movement and $D$ the density (Nelson and Mowrer, 2002). In other words, we used a different measurement method to obtain the flows. However, it should be note that $F_{s}$ and $\hat{F}_{s}$ have the same units (in per/s $\mathrm{m}$ ) as shown in Figure 5.

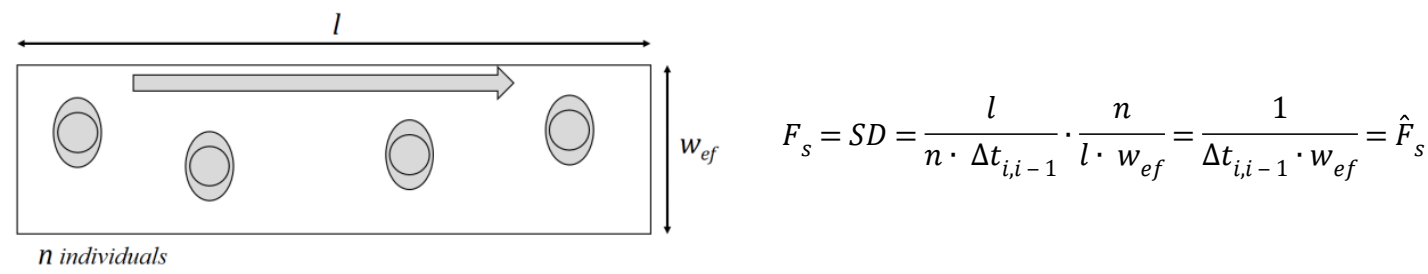


Fig. 5. Equality of $\hat{F}_{S}$ and $F_{S}$ units.

Note that the instantaneous specific flow can be easily defined by the proposed measurement method (i.e. the time intervals $\left(\Delta t_{i, i-1}\right)$ are just the difference between the frame of a participant and the frame of the next one who crosses the reference line). The advantage of using the instantaneous specific flow is the possibility to produce probability distributions instead of using constant/average values. The disadvantage is the very high values produced when time intervals between two subjects are too small. This problem may be addressed by excluding the extreme values (outliers) from data samples. The proposed methods for fences definition and elimination of outliers can be found in (Maronna and Yohai, 1995; Hubert and Vandervieren, 2008; Brys et al., 2004), because data samples of instantaneous flow often are skewed. In the present paper, we used the calculus of the medcouple, which is a robust measure of skewness introducing a correction to Tukey test (Turkey, 1977), based on the first and third quartiles and the IQR (interquartile range).

The data processing was focused on the occurrence of flows under different conditions. Therefore, we made a classification of the observed flows as follows:

$$
\hat{F}_{(X, T, h)_{i}}=\frac{F P S}{\left(F r_{(X, T, h)_{i}}-F r_{(X, T, h)_{i-1}}\right) \cdot W_{X}}
$$

Where:

$\hat{F}_{X_{i}} \quad$ - instantaneous specific flow of the $i$-th participant;

$X=H, V \quad$ - subscript to define the walkway flow (H- horizontal) or the rail car flow (Vvertical)

$T=C, U$ - subscript to define the flow under merging (C- constrained) or no merging conditions (U- unconstrained);

$h \quad$ - subscript to define the height differential of the rail car exit (in this study $0,0.8$ or $1.2 \mathrm{~m}$ );

$\mathrm{Fr}_{X_{i}} \quad$ - frame when the body of the $i$-th participant crosses the reference line;

$F r_{X_{i-1}} \quad$ - frame when the body of the previous participant crosses the reference line;

$W_{X} \quad$ - total width (in m). It can be $W_{V}$ (rail car exit width) or $W_{H}$ (walkway width);

FPS - video frame rate (in this study 29.97 frames/s).

Table 3 shows the different categories of flows considered.

\begin{tabular}{|c|l|l|c|}
\hline Flow & \multicolumn{1}{|c|}{ Class } & \multicolumn{1}{c|}{ Type } & h (m)* \\
\hline$\hat{F}_{H, U, 0}$ & Horizontal (from the walkway) & Unconstrained (no merging) & 0 \\
\hline$\hat{F}_{H, C, 0}$ & Horizontal (from the walkway) & Constrained (merging) & 0 \\
\hline$\hat{F}_{H, C, 0.8}$ & Horizontal (from the walkway) & Constrained (merging) & 0.8 \\
\hline$\hat{F}_{H, C, 1.2}$ & Horizontal (from the walkway) & Constrained (merging) & 1.2 \\
\hline$\hat{F}_{V, U, 0}$ & Vertical (from the rail car exit) & Unconstrained (no merging) & 0 \\
\hline$\hat{F}_{V, C, 0}$ & Vertical (from the rail car exit) & Constrained (merging) & 0 \\
\hline$\hat{F}_{V, U, 0.8}$ & Vertical (from the rail car exit) & Unconstrained (no merging) & 0.8 \\
\hline$\hat{F}_{V, C, 0.8}$ & Vertical (from the rail car exit) & Constrained (merging) & 0.8 \\
\hline$\hat{F}_{V, U, 1.2}$ & Vertical (from the rail car exit) & Unconstrained (no merging) & 1.2 \\
\hline$\hat{F}_{V, C, 1.2}$ & Vertical (from the rail car exit) & Constrained (merging) & 1.2 \\
\hline${ }^{*}$ Height differential of rail car exit & & \\
\hline
\end{tabular}

Table 3. Flow categories for the analysis.

According to this classification, the data for the repeated tests were combined, producing a set of 
10 flow samples for the analysis:

$N_{S}=\left\{n_{H, U, 0}, n_{H, C, 0^{\prime}}, n_{H, C, 0.8}, n_{H, C, 1.2^{2}}, n_{V, U, 0^{0}}, n_{V, C, 0^{\prime}}, n_{V, U, 0.8^{\prime}}, n_{V, C, 0.8}, n_{V, U, 1.2}, n_{V, C, 1.2}\right\}$

Where:

$N_{S}$ - The set of flow samples in different conditions;

$n_{X, T, h}$ - sample of flows $X$-th (H- horizontal or V- vertical), $T$-th (C - Constrained or U unconstrained) and $h$ (heights differences of the rail car exit of $0,0.8$ or $1.2 \mathrm{~m}$ ).

\section{Results}

\subsection{Flow distributions and hypothesis testing}

Table 4 shows the statistical parameters of the instantaneous specific flow distributions. The data are presented independently, given the different possible uses of this data. Mean values in table 4 could be assumed as the specific flows. The observed flows varied depending on the occurrence of merging and the height differential of the rail car exit. This leads to formulate the following hypotheses:

Hypothesis 1: People in the tunnel walkway affected the train exit flow. Hypothesis 2: People exiting the rail car affected the tunnel walkway flow. Hypothesis 3: Height differential affected the rail car exit flow.

These hypotheses were tested using the Mann-Whitney-Wilcoxon (MWW) (Mann and Whitney, 1947; Fay et al, 2010), the Two-sample Kolmogorov-Smirnov (K-S) test (Stephens, 1974) and the Welch's $t$-test (Welch) (Ruxton, 2006).

\begin{tabular}{|c|c|c|c|c|c|c|}
\hline Flow & \# & $\begin{array}{c}\text { Mean } \\
\text { [per/s m] }\end{array}$ & $\underset{[\text { S.Der/s m] }}{\text { S.D. }}$ & $\begin{array}{c}95 \% \text { half } \\
\text { confidence } \\
\text { interval }[\text { per/s m] }\end{array}$ & Skewness & Kurtosis \\
\hline$\hat{F}_{H, U, 0}$ & 87 & 1.51 & 0.10 & 0.46 & 0.238 & -0.444 \\
\hline$\hat{F}_{H, C, 0}$ & 228 & 1.44 & 0.15 & 1.15 & 2.398 & 6.303 \\
\hline$\hat{F}_{H, C, 0.8}$ & 126 & 1.09 & 0.11 & 0.62 & 2.117 & 6.082 \\
\hline$\hat{F}_{H, C, 1.2}$ & 104 & 0.95 & 0.10 & 0.52 & 1.084 & 1.304 \\
\hline$\hat{F}_{V, U, 0}$ & 55 & 2.59 & 0.50 & 1.84 & 2.185 & 4.066 \\
\hline$\hat{F}_{V, C, 0}$ & 217 & 1.71 & 0.21 & 1.59 & 2.366 & 5.895 \\
\hline$\hat{F}_{V, U, 0.8}$ & 30 & 1.17 & 0.11 & 0.29 & 0.206 & -0.732 \\
\hline$\hat{F}_{V, C, 0.8}$ & 100 & 0.78 & 0.05 & 0.26 & 1.154 & 2.352 \\
\hline$\hat{F}_{V, U, 1.2}$ & 13 & 0.90 & 0.19 & 0.32 & 1.248 & 0.501 \\
\hline$\hat{F}_{V, C, 1.2}$ & 87 & 0.51 & 0.04 & 0.21 & 1.145 & 1.371 \\
\hline
\end{tabular}

Table 4. Main parameters of instantaneous specific flow distributions.

Tables 5-7 show the results of the statistical hypotheses (level of significance $\alpha=0.05$ ). As expected, the presence of people in the walkway affected the rail car exit flow $\left(\mathrm{H}_{0}\right.$ rejected using MWW, K-S and Welch statistical tests). In addition, rail car exit flow affected the walkway flow $\left(\mathrm{H}_{0}\right.$ rejected using MWW, K-S and Welch tests). Furthermore, results in Table 7 show that the height differential of the rail car exit affected the exiting process $\left(\mathrm{H}_{0}\right.$ rejected using MWW, K-S and Welch tests).

\begin{tabular}{|c|c|c|c|c|c|c|}
\hline \multirow{2}{*}{ Pair of samples } & \multicolumn{2}{|c|}{ MWW } & \multicolumn{2}{c|}{ K-S } & \multicolumn{2}{c|}{ Welch } \\
\cline { 2 - 6 } & Statistics & $\mathbf{H}_{\mathbf{0}}$ & Statistics & $\mathbf{H}_{\mathbf{0}}$ & Statistics & $\mathbf{H}_{\mathbf{0}}$ \\
\hline
\end{tabular}




\begin{tabular}{|c|c|c|l|c|l|c|c|}
\hline \multicolumn{2}{|c|}{} & comparison & & comparison & & comparison & \\
\hline$n_{V, U, 0}$ & $n_{V, C, 0}$ & $5.91 \geq 1.96$ & Rejected & $0.57>0.21$ & Rejected & $3.23 \geq 1.99$ & Rejected \\
\hline$n_{V, U, 0.8}$ & $n_{V, C, 0.8}$ & $5.21 \geq 1.96$ & Rejected & $0.53>0.28$ & Rejected & $6.31 \geq 2.02$ & Rejected \\
\hline$n_{V, U, 1.2}$ & $n_{V, C, 1.2}$ & $4.51 \geq 1.96$ & Rejected & $0.67>0.40$ & Rejected & $4.13 \geq 2.16$ & Rejected \\
\hline
\end{tabular}

Table 5. Statistical tests results when comparing constrained and unconstrained flows from the rail car exit. Hypothesis 1.

\begin{tabular}{|c|c|c|c|c|c|c|c|}
\hline \multirow{2}{*}{ Pair of samples } & \multicolumn{2}{|c|}{ MWW } & \multicolumn{2}{c|}{ K-S } & \multicolumn{2}{c|}{ Welch } \\
\cline { 2 - 8 } & & $\begin{array}{c}\text { Statistics } \\
\text { comparison }\end{array}$ & $\mathbf{H}_{\mathbf{0}}$ & $\begin{array}{c}\text { Statistics } \\
\text { comparison }\end{array}$ & $\mathbf{H}_{\mathbf{0}}$ & $\begin{array}{c}\text { Statistics } \\
\text { comparison }\end{array}$ & $\mathbf{H}_{\mathbf{0}}$ \\
\hline$n_{H, U, 0}$ & $n_{H, C, 0}$ & $4.15 \geq 1.96$ & Rejected & $0.32>0.17$ & Rejected & $6.25 \geq 1.96$ & Rejected \\
\hline$n_{H, U, 0}$ & $n_{H, C, 0.8}$ & $6.87 \geq 1.96$ & Rejected & $0.47>0.19$ & Rejected & $8.59 \geq 1.96$ & Rejected \\
\hline$n_{H, U, 0}$ & $n_{H, C, 1.2}$ & $7.42 \geq 1.96$ & Rejected & $0.50>0.20$ & Rejected & $7.65 \geq 1.96$ & Rejected \\
\hline
\end{tabular}

Table 6. Statistical tests results when comparing constrained and unconstrained walkway flows.

Hypothesis 2.

\begin{tabular}{|c|c|c|c|c|c|c|c|}
\hline \multirow{2}{*}{ Pair of samples } & \multicolumn{2}{|c|}{ MWW } & \multicolumn{2}{c|}{ K-S } & \multicolumn{2}{c|}{ Welch } \\
\cline { 3 - 8 } & $\begin{array}{c}\text { Statistics } \\
\text { comparison }\end{array}$ & $\mathbf{H}_{\mathbf{0}}$ & $\begin{array}{c}\text { Statistics } \\
\text { comparison }\end{array}$ & $\mathbf{H}_{\mathbf{0}}$ & $\begin{array}{c}\text { Statistics } \\
\text { comparison }\end{array}$ & $\mathbf{H}_{\mathbf{0}}$ \\
\hline$n_{V, C, 0}$ & $n_{V, C, 0.8}$ & $7.32 \geq 1.96$ & Rejected & $0.40>0.16$ & Rejected & $8.29 \geq 1.96$ & Rejected \\
\hline$n_{V, C, 0}$ & $n_{V, C, 1.2}$ & $11.71 \geq 1.96$ & Rejected & $0.69>0.17$ & Rejected & $10.82 \geq 1.96$ & Rejected \\
\hline$n_{V, C, 0.8}$ & $n_{V, C, 1.2}$ & $7.40 \geq 1.96$ & Rejected & $0.50>0.20$ & Rejected & $7.81 \geq 1.96$ & Rejected \\
\hline$n_{V, U, 0}$ & $n_{V, U, 0.8}$ & $5.98 \geq 1.96$ & Rejected & $0.65>0.31$ & Rejected & $5.54 \geq 2.00$ & Rejected \\
\hline$n_{V, U, 0}$ & $n_{V, U, 1.2}$ & $5.01 \geq 1.96$ & Rejected & $0.79>0.42$ & Rejected & $6.32 \geq 2.00$ & Rejected \\
\hline$n_{V, U, 0.8}$ & $n_{V, U, 1.2}$ & $2.63 \geq 1.96$ & Rejected & $0.49>0.45$ & Rejected & $2.47 \geq 2.08$ & Rejected \\
\hline
\end{tabular}

Table 7. Statistical tests results when comparing flows of different height differentials of the rail car exit. Hypothesis 3.

\subsection{Unconstrained vs constrained flows}

From the statistical tests of section 4.1, it is possible to say that walkway flow and rail car exit flow decreased due to the occurrence of merging. To measure this, we introduced the coefficient of constraint defined as the proportion of reduction of the mean of unconstrained flow (no merging) when compared with the mean of constrained flow (merging):

$$
k_{C(X, h)}=\frac{M\left(\hat{F}_{(X, C, h)}\right)}{M\left(\hat{F}_{(X, U, h)}\right)}
$$

Where:

$k_{C(X, h)}$ - coefficient of constraint for flows $X(\mathrm{H}$ - horizontal or $\mathrm{V}$ - vertical) and with $\mathrm{h}$ (the height differential of the rail car exit in $\mathrm{m})$;

$M(Z)$ - mean (expected) value of $Z$ variable.

Subscripts were previously defined in equation (2).

The confidence interval for $k_{C(X, h)}$ can be calculated by:

$\operatorname{Pr}_{k_{C(X, h)}}\left(\left.k_{C(X, h)}\right|_{\min }<k_{C(X, h)}<\left.k_{C(X, h)}\right|_{\max }\right)=P_{k}$

Where:

$P_{k}$ - confidence interval for $k_{C(X, h)}$. 
$\left.k_{C(X, h)}\right|_{\min }=\frac{M\left(\hat{F}_{(X, C, h)}\right)-\Delta M\left(\hat{F}_{(X, C, h)}\right)}{M\left(\hat{F}_{(X, U, h)}\right)+\Delta M\left(\hat{F}_{(X, U, h)}\right)}$

$\left.k_{C(X, h)}\right|_{\text {max }}= \begin{cases}\frac{M\left(\hat{F}_{(X, C, h)}\right)+\Delta M\left(\hat{F}_{(X, C, h)}\right)}{M\left(\hat{F}_{(X, U, h)}\right)-\Delta M\left(\hat{F}_{(X, U, h)}\right)} & \text { if } \frac{M\left(\hat{F}_{(X, C, h)}\right)+\Delta M\left(\hat{F}_{(X, C, h)}\right)}{M\left(\hat{F}_{(X, U, h}\right)-\Delta M\left(\hat{F}_{(X, U, h)}\right)} \leq 1 \\ 1 & \text { if } \frac{M\left(\hat{F}_{(X, C, h)}\right)+\Delta M\left(\hat{F}_{(X, C, h)}\right)}{M\left(\hat{F}_{(X, U, h}\right)-\Delta M\left(\hat{F}_{(X, U, h)}\right)}>1\end{cases}$

$\Delta M(Z)$ - half of confidence interval of the mean of $Z$; being the variable $Z \hat{F}_{(X, C, h)}$ or $\hat{F}_{(X, U, h)}$.

$$
\begin{gathered}
P_{k}=\operatorname{Pr}\left(k_{C(X, h)}>\left.k_{C(X, h)}\right|_{\min }\right) \times \operatorname{Pr}\left(k_{C(X, h)}<\left.k_{C(X, h)}\right|_{\text {max }}\right) \\
\operatorname{Pr}\left(k_{C(X, h)}>\left.k_{C(X, h)}\right|_{\min }\right)=\operatorname{Pr}\left(k_{C(X, h)}<\left.k_{C(X, h)}\right|_{\text {max }}\right)=\operatorname{Pr} \\
\left(M\left(\hat{F}_{(X, C, h)}\right)>\left(M\left(\hat{F}_{(X, C, h)}\right)-\Delta M\left(\hat{F}_{(X, C, h)}\right)\right)\right) \times \operatorname{Pr}\left(M\left(\hat{F}_{(X, C, h)}\right)<\left(M\left(\hat{F}_{(X, C, h)}\right)+\Delta M\left(\hat{F}_{(X, C, h)}\right)\right)\right)
\end{gathered}
$$

As known:

$\operatorname{Pr}\left(M\left(\hat{F}_{(X, C, h)}\right)<\left(M\left(\hat{F}_{(X, C, h)}\right)+\Delta M\left(\hat{F}_{(X, C, h)}\right)\right)\right)=1-\propto / 2$

$\propto \quad$ - significance level of calculated mean confidence interval.

Then, from (8) - (10), if $\alpha=0.05, P_{k}=0.9037$

Table 8 shows the coefficients of constraint produced. It is apparent that the rail car exit flow was more affected than the walkway flow when merged. What is interesting about the data in Table 8 is the impact produced by the height differential (h). While this had a slightly influence on the rail car exit flow, the coefficients of constrain of the walkway flow decreased by $23 \%$ when comparing $\mathrm{h}=0$ with $\mathrm{h}=0.8$ and by $32 \%$ when comparing $\mathrm{h}=0$ with $\mathrm{h}=1.2$. This could be due to deference behaviours of walkway participants.

\begin{tabular}{|c|c|c|c|c|}
\hline Flow & $\mathbf{h}(\mathbf{m})^{*}$ & $\boldsymbol{k}_{\boldsymbol{C}(\boldsymbol{X}, \boldsymbol{h})}$ & $\left.\boldsymbol{k}_{\boldsymbol{C}(\boldsymbol{X}, \boldsymbol{h})}\right|_{\min }$ & $\left.\boldsymbol{k}_{\boldsymbol{C}(\boldsymbol{X}, \boldsymbol{h})}\right|_{\max }$ \\
\hline \multirow{3}{*}{ Rail car exit } & 0 & 0.66 & 0.48 & 0.92 \\
\cline { 2 - 5 } & 0.8 & 0.67 & 0.57 & 0.79 \\
\cline { 2 - 5 } & 1.2 & 0.57 & 0.43 & 0.78 \\
\hline \multirow{3}{*}{ Walkway } & 0 & 0.95 & 0.80 & 1.00 \\
\cline { 2 - 5 } & 0.8 & 0.72 & 0.61 & 0.85 \\
\cline { 2 - 5 } & 1.2 & 0.63 & 0.53 & 0.74 \\
\hline *Height differential of rail car exit
\end{tabular}

Table 8. Coefficients of constraint and confidence bounds.

\subsection{Interdependence of flows when merge}

This section explores the interdependence of flows when merged. We assumed that the mean of the rail car exit flow and the mean of the walkway flow were mutually dependent. The data analysis consisted of transforming the independent flow samples into paired samples. Hence, we explored a novel way of data clustering: 1) Clustering Type I where clusters are defined as groups of participants who interact each other during the merging process and Clustering Type II where clusters are defined as time intervals during the merging process. 
Due to clustering is not an automatic task but an iterative process, we selected different groups of participants for Clustering Type I (6, 8 and 10 participants) and time intervals for Clustering Type II $(5,7.5$ and $10 \mathrm{~s})$. This was based on a detailed analysis of video recordings (frame by frame). Then, paired samples were plotted and analysed to estimate the relationship between the variables (walkway flow and rail car exit flow). The ordinary less-square linear regression through the origin was employed (Eisenhauer, 2003). When the walkway flow is zero the rail car exit flow should be zero as well, due to the absence of merging.

Figures 6-11 show the interdependence of flows when merged. The straight line in figures, with a slope equal to 1 , was used as a reference of no reciprocal influence (i.e. both flows have the same value). This reference line also represents a merging ratio of 50:50. The relationship between the flows varied considerably during the merge period. Data points above the reference line were rail car exit bias while data points below the reference line were walkway bias. As expected, data clustering affected the results. Despite this, the slopes of the regression lines (dashed lines) were below the reference line (straight line) in all cases. The lower the slope of the regression line the higher the priority of the walkway flow.

Tables 9 and 10 display the slopes of the regression lines, the correlation coefficients and the merging ratios produced. The regression lines fit data well with values of the correlation coefficients between 0.67 and 0.99 . Thus, it is argued that the slopes of the lines are valid to describe the relationship between flows. The bias in the evacuation was slightly in favour of the walkway when there was not height differential. In this case, for $\mathrm{h}=0$, the slopes of the regression lines ranged from 0.87 to 0.97 in Clustering Type I and from 0.83 to 0.96 in Clustering Type II. Contrary to expectations, we found a moderate dominance of walkway flow with a height differential in the rail car exit of $h=0.8$. The higher variation was found in this case with slopes of the regression lines ranged from 0.79 to 0.92 in Clustering Type I while Clustering Type II produced slopes from 0.81 to 0.84 . Less variation in the slopes of the regression lines was observed for $\mathrm{h}=1.2$ with lower values ranged from 0.53 to 0.65 and from 0.53 to 0.63 in Clustering Type I and II respectively. Based on this, it is possible to say that, in this case, walkway participants took a clear priority over the train participants.

Groups of 6 participants

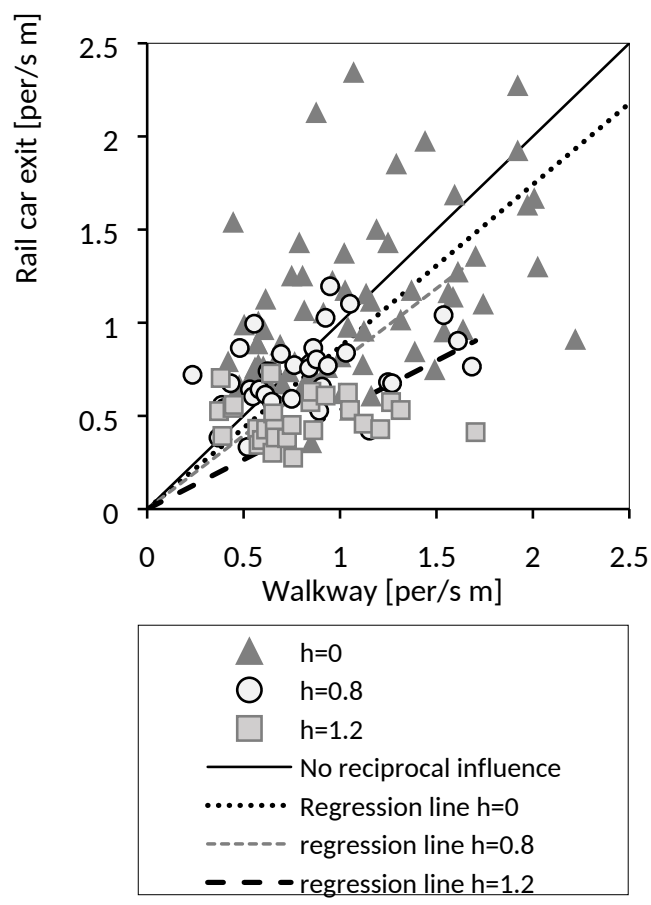

Fig. 6. Correlation between flows. Clustering Type
Time intervals of $5 \mathrm{~s}$

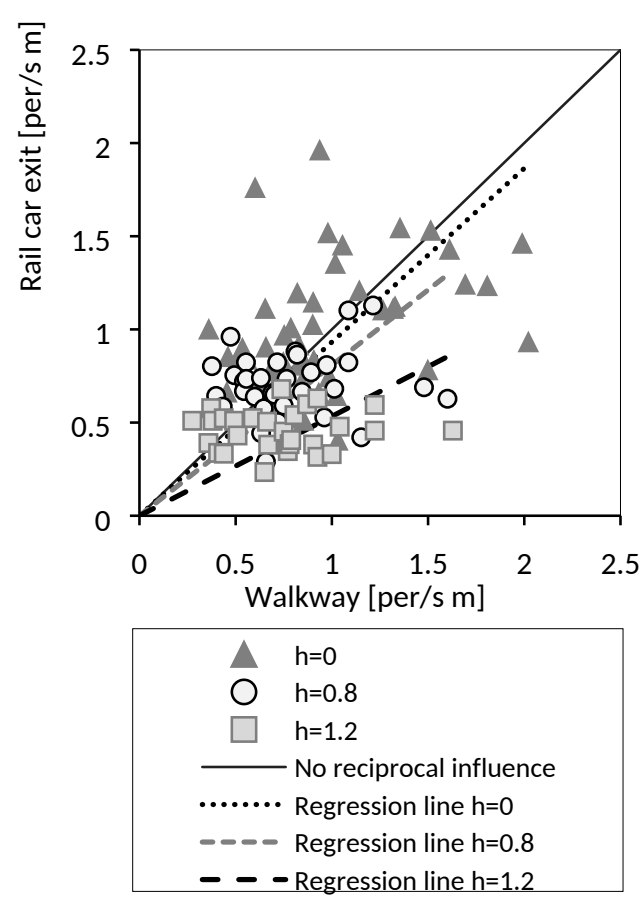

Fig. 7. Correlation between flows. Clustering 
I: groups of 6 participants.

\section{Groups of 8 participants}
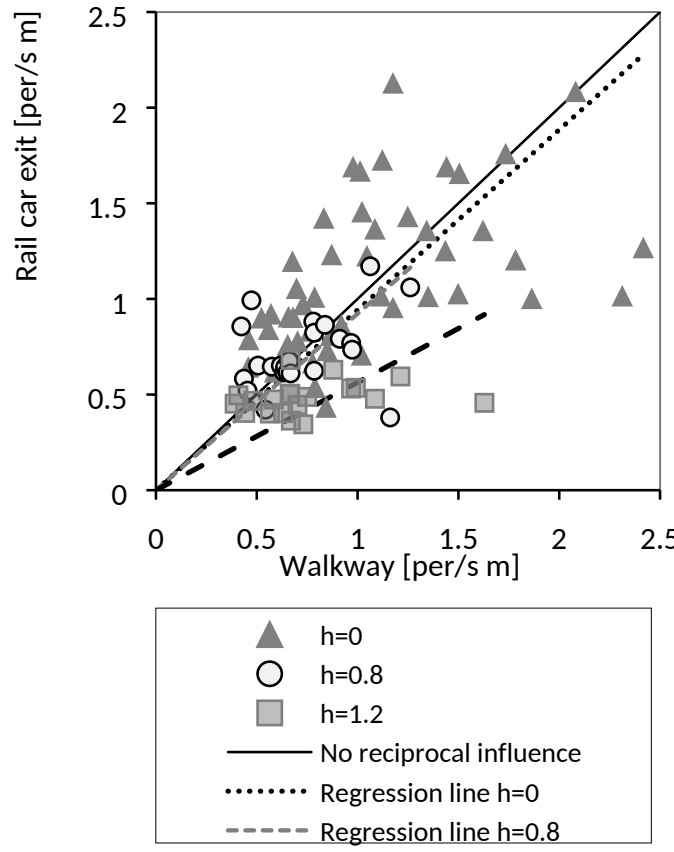

Fig. 8. Correlation between flows. Clustering

Type I: groups of 8 participants.

Groups of 10 participants

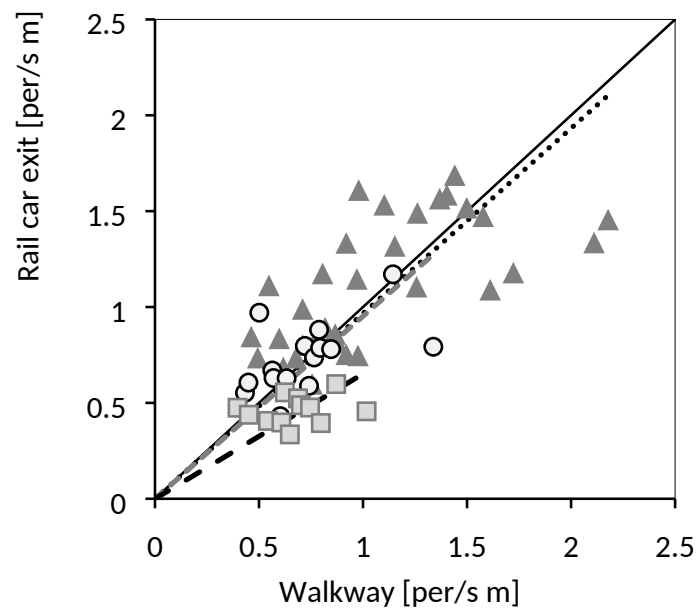

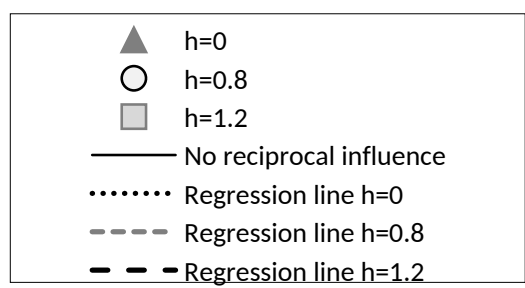

Fig. 10. Correlation between flows. Clustering Type I: groups of 10 participants.
Type II: time intervals of $5 \mathrm{~s}$.

Time intervals of $7.5 \mathrm{~s}$
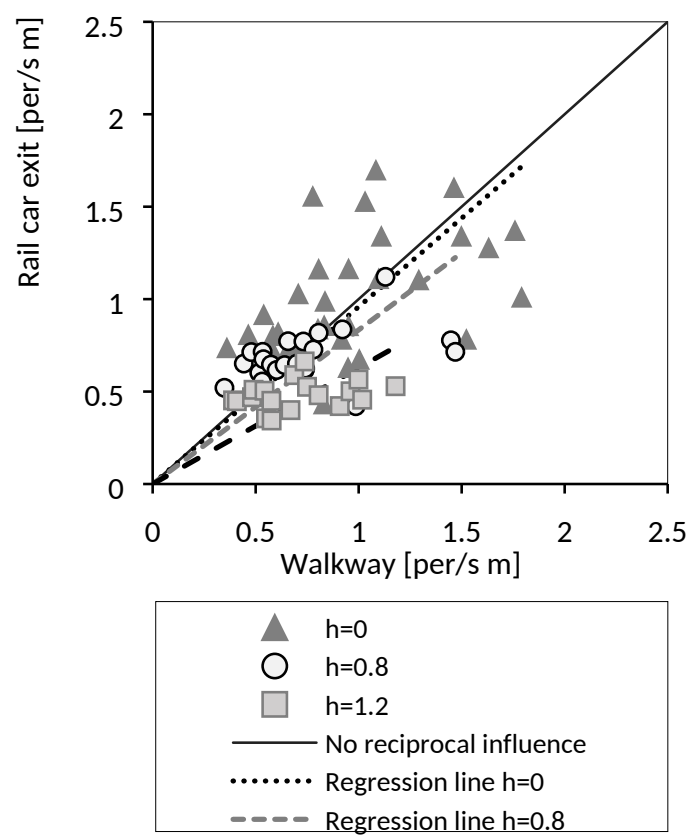

Fig. 9. Correlation between flows. Clustering Type II: time intervals of $7.5 \mathrm{~s}$.

Time intervals of $10 \mathrm{~s}$
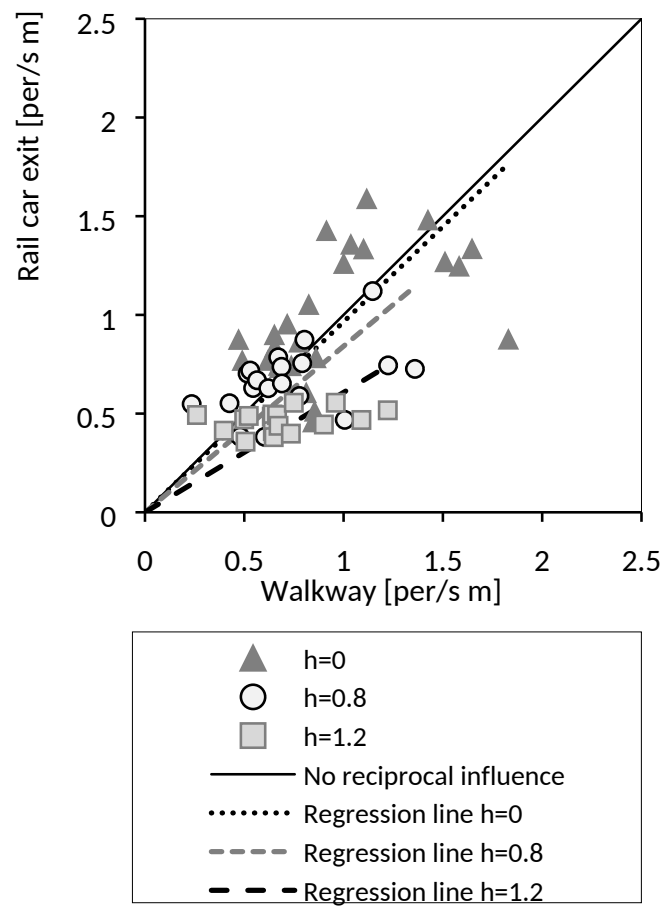

Fig. 11. Correlation between flows. Clustering Type II: time intervals of $10 \mathrm{~s}$.

The merging ratios in Tables 9 and 10 also provide an overview of the merging patterns through the quantitative measurement of the preference between the walkway flow over the rail car exit flow. The average merging ratios (walkway/rail car exit) derived from this analysis were 53:47 for $\mathrm{h}=0,58: 42$ for $\mathrm{h}=0.8$ and $71: 29$ for $\mathrm{h}=1.2$. 


\begin{tabular}{|c|c|c|c|c|c|}
\hline $\begin{array}{c}\text { Clustering } \\
\text { Type I }\end{array}$ & $\#$ & $\mathbf{h}(\mathbf{m}) *$ & Slope & $\begin{array}{c}\text { Correlation } \\
\text { coefficient (R) }\end{array}$ & $\begin{array}{c}\text { Merging ratio } \\
\text { walkway:rail car exit }\end{array}$ \\
\hline \multirow{4}{*}{6 per } & 70 & 0 & 0.87 & 0.99 & $57: 43$ \\
\cline { 2 - 6 } & 35 & 0.8 & 0.79 & 0.74 & $61: 39$ \\
\cline { 2 - 6 } & 28 & 1.2 & 0.53 & 0.74 & $74: 26$ \\
\hline \multirow{3}{*}{8 per } & 49 & 0 & 0.94 & 0.89 & $53: 47$ \\
\cline { 2 - 6 } & 23 & 0.8 & 0.92 & 0.92 & $54: 46$ \\
\cline { 2 - 6 } & 20 & 1.2 & 0.56 & 0.67 & $72: 28$ \\
\hline \multirow{3}{*}{10 per } & 33 & 0 & 0.97 & 0.81 & $52: 48$ \\
\cline { 2 - 6 } & 15 & 0.8 & 0.80 & 0.86 & $60: 40$ \\
\cline { 2 - 6 } & 12 & 1.2 & 0.65 & 0.87 & $68: 32$ \\
\hline *Height differential of rail car exit \\
Table 9. Slopes, correlation coefficients and associates merging flows for Clustering Type I.
\end{tabular}

\begin{tabular}{|c|c|c|c|c|c|}
\hline $\begin{array}{c}\text { Clustering } \\
\text { Type II }\end{array}$ & $\#$ & $\mathbf{h}(\mathbf{m}) *$ & Slope & $\begin{array}{c}\text { Correlation } \\
\text { coefficient (R) }\end{array}$ & $\begin{array}{c}\text { Merging ratio } \\
\text { walkway:rail car exit }\end{array}$ \\
\hline \multirow{3}{*}{$5 \mathrm{~s}$} & 47 & 0 & 0.93 & 0.91 & $54: 46$ \\
\cline { 2 - 6 } & 34 & 0.8 & 0.81 & 0.77 & $60: 40$ \\
\cline { 2 - 6 } & 28 & 1.2 & 0.53 & 0.71 & $74: 26$ \\
\hline \multirow{4}{*}{$7.5 \mathrm{~s}$} & 32 & 0 & 0.96 & 0.89 & $52: 48$ \\
\cline { 2 - 6 } & 22 & 0.8 & 0.83 & 0.68 & $59: 41$ \\
\cline { 2 - 6 } & 18 & 1.2 & 0.63 & 0.74 & $69: 31$ \\
\hline \multirow{3}{*}{$10 \mathrm{~s}$} & 25 & 0 & 0.96 & 0.86 & $52: 48$ \\
\cline { 2 - 6 } & 19 & 0.8 & 0.84 & 0.80 & $58: 42$ \\
\cline { 2 - 6 } & 17 & 1.2 & 0.61 & 0.68 & $70: 30$ \\
\hline
\end{tabular}

*Height differential of rail car exit

Table 10. Slopes, correlation coefficients and associates merging flows for Clustering Type II.

\subsection{Behaviour of participants}

A proportion of elder people was used in the experiment. Therefore, the major concern was the height differential of the rail car exit. Participants were asked to participate before every change in the exit configuration due to ethical issues. Table 11 shows the number of participants that quit the experiment. What is interesting in the data is that participants gradually refused to take part in the tests. Some felt unable to overcome height differential in advance while others gave up before repeating. They were asked and they explained that they did their best (i.e. as if they were in a real situation).

\begin{tabular}{|c|c|c|c|c|}
\hline \multirow{2}{*}{ Test } & \multirow{2}{*}{$\boldsymbol{h}_{\boldsymbol{v}}(\mathrm{m})$} & \multirow{2}{*}{ Group } & \multicolumn{2}{|c|}{ Participants who refused } \\
\cline { 4 - 5 } & & $\#$ & $\mathbf{\%}$ \\
\hline Test 9 & 0.8 & \multirow{4}{*}{ Red } & 3 & 7.69 \\
\hline Test 11 & 0.8 & 4 & 10.26 \\
\hline Test 14 & 1.2 & & 9 & 23.08 \\
\hline Test 16 & 1.2 & & 11 & 28.21 \\
\hline & & & & \\
\hline Test 10 & 0.8 & \multirow{4}{*}{ Yellow } & 1 & 2.63 \\
\hline Test 12 & 0.8 & 3 & 7.89 \\
\hline Test 13 & 1.2 & & 10 & 26.32 \\
\hline Test 15 & 1.2 & & 12 & 31.58 \\
\hline
\end{tabular}

Table 11. Number of participants who quit the experiment. 


\title{
An experimental data-set on merging flows in rail tunnel evacuation
}

\author{
Arturo Cuesta (cuestaar@unican.es); Orlando Abreu (abreu@unican.es); Adriana Balboa \\ (balboaa@unican.es) and Daniel Alvear (alveard@unican.es \\ GIDAI Group - Fire Safety- Research and Technology, University of Cantabria \\ Ave. Los Castros, s/n. 39005 Santander. (Spain) \\ Tel.: +34 942201826 Fax: +34 942201873
}

\begin{abstract}
The main purpose of this study was to investigate the impact of merging conditions during evacuation process in rail tunnels. The experiment was carried out in a mock-up of a rail car with a single exit towards a lateral corridor. Eight exit configurations were tested involving 77 participants with a reasonable proportion of ageing subjects (age mean 48; standard deviation 15; range 18-74). New measurements and data processing methods were proposed and used. Observations from video recordings complemented the quantitative analysis revealing behavioural patterns of participants. As confirmed by results, the occurrence of merging had a negative effect during evacuation. The rail car exit flow and the walkway flow decreased when merge. The relationship between both flows varied considerably during the merging period. However, we found that the higher the height differential of the rail car exit the more dominance of the walkway flow. The bias in the evacuation was slightly in favour of the walkway when there was not height differential of the rail car exit. Contrary to expectations, we found a moderate dominance of walkway flow with a height differential of the rail car exit of $0.8 \mathrm{~m}$. However, there was a clear dominance of the walkway flow over the rail car exit flow when the rail car exit was $1.2 \mathrm{~m}$ in height. We also found no gender playing a role in deference behaviour (male helping female).
\end{abstract}

Keywords: Rail tunnel evacuation, merging flows, experimental data-set, deference behaviour

\section{Introduction}

Safety of rail passengers is such a relevant research issue for emergency response planners, safety managers, transport engineers, rail operators and policy makers. One of the main concerns of rail safety is that high capacity trains operate in tunnels and underground spaces. As long as "hot" incidents occur inside the tunnel (fire, explosion followed by fire, emission of toxic smoke or gasses), the priority is to reach an external place for the evacuation (i.e. the closest station). However, this is not always possible and passengers may be required to leave the train and then evacuate the tunnel (e.g. by a cross passage or the tunnel portal) away from the threat as fast as possible. This is bound to be problematic since train exit flows and walkway flow are likely to be constrained due to merging conditions, increasing the required time for evacuees to reach a safe place (Fridolf et al. 2014a). In such conditions, an appropriate design and an effective evacuation strategy can save lives (Alvear et al. 2013). As far as rail tunnel design concerned, national guidelines, regulations and standards provide parameters to get a safety evacuation. Although on the whole, there is a lack of homogeneity in evacuation design requirements. In addition, many accident reports have described a lack of training and preparedness in emergency procedures (Train door Emergency Egress, 2004). To address this, rail companies, authorities and stakeholders usually perform full-scale drills. These tests have various problems, such as their lack of realism and their economic cost. Furthermore, it is well known that single trials produce limited information of the variety of potential outcomes seen in evacuation processes.

On the other hand, computer modelling analysis has advantages such as the reduction of the actual trials and the increase of the number of scenarios in the analysis. Simulation models can provide consistent and accurate results when reliable inputs are used (Capote et al., 2012a; 2012b). While 
the potential of such approach is clear (Cuesta et al., 2014; 2016; Wang and Lo, 2014; Weyenberge and Deckers, 2014), computer modelling analyses are not always supported by empirical data, since there is a slight availability of sufficiently detailed, comprehensive and relevant data for supporting design requirements and/or computer modelling analyses. There are a limited number of data-sets in the literature describing the performances of evacuees in rail tunnels including train exit flow rates (Fridolf et al., 2014a; 2016; Marlos and Pollar, 2013: Kim et al., 2012; Oswald et al., 2008; 2011; Nórén and Winér, 2003), walking speeds in smoky conditions (Seike, et al., 2016; Fridolf et al., 2014b; Frantzich and Nilsson, 2004), walking speeds on a tunnel walkway (Lundstrom et al., 2014) and exit strategies to overcome the height of train exits (Oswald et al., 2008). Moreover, even though many authors have reported distinct issues regarding safety in rail tunnels, there has been little research on evacuation. The purpose of the present study is therefore to analyze the potential impact of merging conditions during evacuation in rail tunnels by collecting empirical data that are analysed using mathematically based methods, in particular statistics. The paper is organized as follows. Section 2 briefly discusses the relevant empirical studies on pedestrian dynamics on merging configurations. While Section 3 describes the controlled laboratory experiments for different train exit configurations and the measurement methods used, Section 4 presents results mainly focused on the reciprocal influence of the merging flows and the behaviour of participants. Finally, Section 5 discusses related work and concludes the paper with some indications for future work.

\section{Empirical studies on pedestrian merging configurations}

Nowadays, there are a limited number of empirical studies which have specifically investigated pedestrian merging flows. These studies can be divided into 1) staircase merging studies and 2) horizontal merging studies.

On the one hand, the former studies are focused on the way in which people from the stair and the floor merge in the stair landings during evacuation. Data are often collected with different methods, background conditions (controlled experiments and evacuation drills), stair configurations and considering different behavioural factors. This leads to disagreements on the findings (Sano et al, 2017). For instance, in (Pauls, 2004) it was claimed that people already in the stair allowed people entering the stair from lower floors to proceed first in congested situations whereas other studies claimed an approximate merging ratio of 50:50 (Hukugo et al., 1985; Boyce et al., 2012; Sano et al., 2015). Some other research works paid attention to the stair configuration (i.e the position of the door in the landing) and its impact on the evacuation time of a floor (Boyce et al., 2012; Melly et al., 2009; Takeichi et al., 2005). The use of simulation tools could provide insights into this aspect (Galea, et al. 2008; Hamacher, et al. 2011).

On the other hand, horizontal merging studies have been traditionally conducted on a single rightangle merging setup (also referred as T-junction). Although several measurement methods have been applied to the study of merging in corridors (Zhang et al., 2011; Craesmeyer et al., 2014) the Voronoi method was found to be the most used (Boltes et al., 2011; Zhang et al., 2011; Zhang et al., 2013) as it is able to resolve the fine structure of the fundamental diagram (Zhang et al., 2011). One finding was that fundamental diagrams of a T-junction flow were different before and after merging because merging process led to a flow restriction (Boltes et al., 2011). Furthermore, the study of (Zhang et al., 2011) showed that fundamental diagrams from different facilities (Tjunction vs straight corridor) were not comparable. When the outflow and the inflow were not equal, a transition between low and high densities appeared in the pedestrian flow. Recent empirical researches explored additional configurations to assess the impact of different merging angles. These studies demonstrated that the merging angle and flow direction had impact on the overall outflow. For instance, one of the main findings was that the higher the merging angle the lower the pedestrian flow (Shiwatoki et al., 2015; Shi et al., 2016). Other finding was that the visual access was likely to produce better throughput than a blocked view of pedestrians while merging (Aghabayk et al., 2014). 
To sum up, while considerable research has been devoted to merging flows, no research has looked into merging during evacuation in rail tunnels. There is a need to determine the cause and effect relationship between the population inside the tunnel and the flow rate capacity of a train exit, as this is expected to have a significant influence on the total evacuation time (Fridolf et al. 2014a). Therefore, the primary objective of our paper is to provide how merging behaviour affects in a right-angle configuration that represents the train exit (with "height differential") and the lateral walkway inside a rail tunnel, providing data collection, processing methods and the datasets for further research so as to better understand the merging process and the impact of interactions among passengers during evacuation.

\section{Experiment set up}

Field experiments in a real-world setting require significant economic cost and organization effort (e.g. a train inside a rail tunnel). Since this study was focused on a primary performance factor, we conducted laboratory experiments at the University of Cantabria (Spain) on the 13th of August 2014. The experiment was carried out in a mock-up of a rail car with a single exit towards a lateral corridor. Different geometry configurations were used to study merging flows. In this section the layout, participants, scenarios, experiment procedure and measurement methods are described.

\subsection{Layout}

Figure 1 shows the experiment setup. The mock-up of the rail car (made of wood) consisted of two ramps leading access to a vestibule adjustable at different heights $(0.20,0.40,0.60,0.80,1.00$ and $1.20 \mathrm{~m})$. The vestibule had an exit with a sliding door able to adjust to different widths $(0.80$ and $1.20 \mathrm{~m}$ ). The walking corridor ( $12 \mathrm{~m}$ in length) was attached to the rail car model to meet the right-angle configuration. The boundary material of the walking corridor was opaque canvas (3 $\mathrm{m}$ in height) solid enough to represent the walls (e.g. blocked vision conditions to participants). Note that the width of the walking corridor could be modified as well. In other words, the experiment setup was flexible enough to easy manipulate the geometry and explore different exit configurations (see Fig. 2).

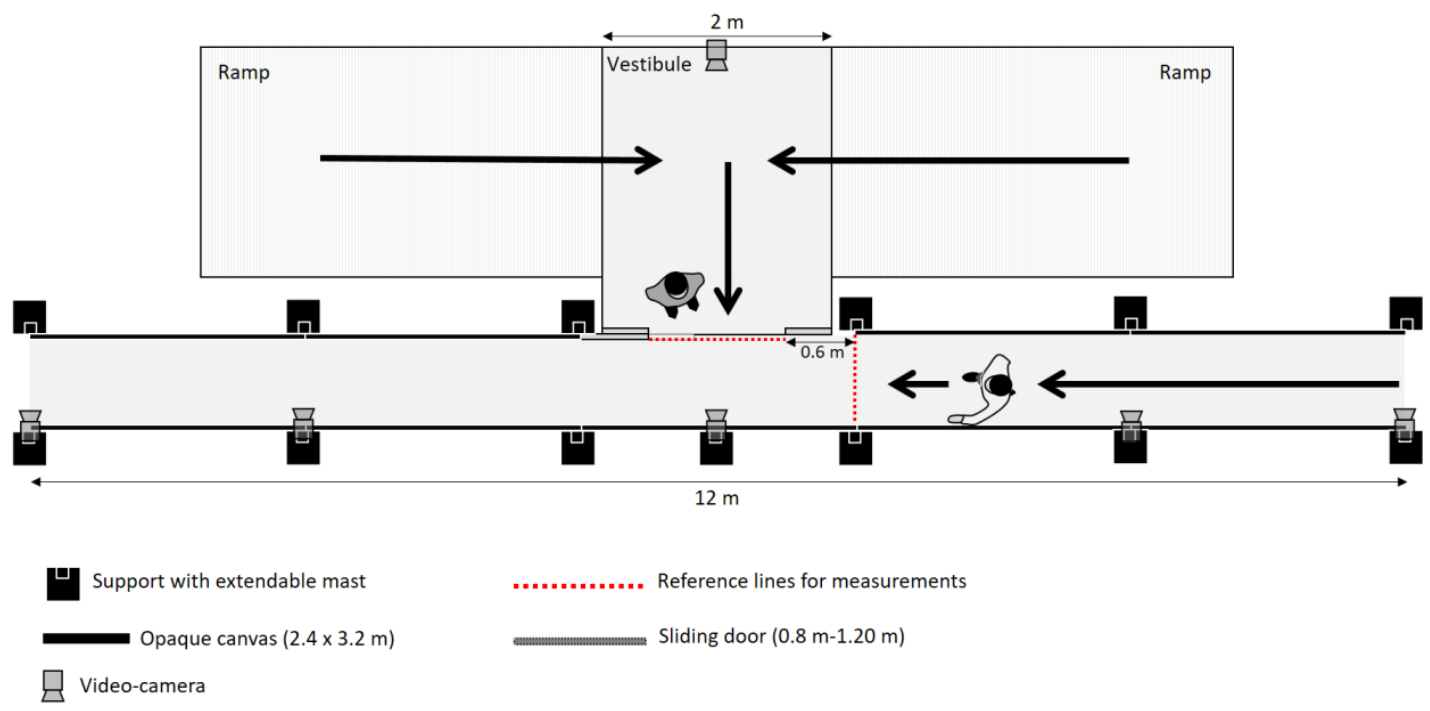

Fig. 1. Experiment setup. 


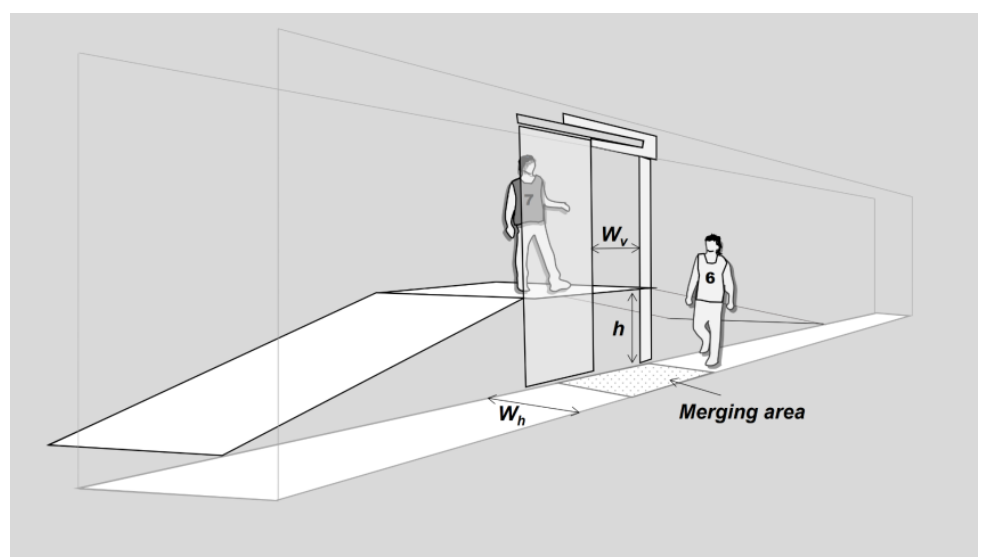

Fig. 2. Independent variables manipulated for testing different exit configurations:1) $W_{v}=$ the width of the train exit, 2) $W_{h}=$ the width of the lateral walkway and 3) $h=$ the height differential of the train exit.

\subsection{Participants}

A deliberate effort was made to recruit a reasonable proportion of ageing subjects to test a sample representative of future rail transport users. Demographic information derived from Eurostat population projections ${ }^{1}$ was used as a reference to recruit the participants. The population demographics are shown in Figure 3. In total 77 participants took part in experiment, 37 women (48\%) and 40 men (52\%). The age of participants varied from 18 to 74 years, with an average of 48 years and a standard deviation 15 years. Due to ethical reasons, no children were used. Participants were volunteers recruited by a company and covered with casualty insurance. They received information and signed an informed consent form beforehand the experiments. As reward, participants were given a raffle ticket for a laptop, a dinner and a spa for two persons. Since the experiments were performed in summer, the participants did not wear jackets, jumpers, coats, etc. However, by $21 \%$ of participants carried backpacks and by $62 \%$ of female participants had their handbags with them during the experiment.

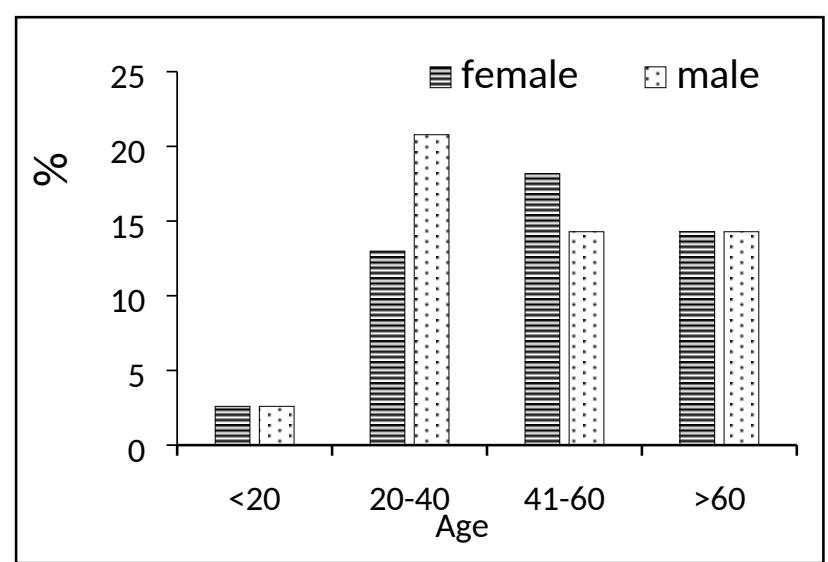

Fig. 3. Age and gender of participants.

\subsection{Experiment procedure}

Table 1 displays the basic information of the tests conducted. The height differential $(h)$ and the width of the train exits $\left(W_{v}\right)$ were based on high speed trains and regional trainsets which operate in Spain. Similarly, the walkway widths $\left(W_{h}\right)$ were taken from (European Commission, 2014). The flexibility of the mock-up allowed us to arrange different exit configurations. In total 16 tests were conducted considering eight exit configurations (see Table 1).

\footnotetext{
${ }^{1}$ Eurostat population projections: http://ec.europa.eu/eurostat/statisticsexplained/index.php/People in the EU \%E2\%80\%93 population projections
} 
The alphabetical order of participant surnames was used as a random sampling method to form the two experimental groups, namely Red group (39 participants) and Yellow group (38 participants). Each participant wore a coloured vest (red or yellow) with a number to be identified during experiment. Two tests were carried out for each exit configuration switching the starting location of the groups (see Table 1). One group was located on the mock-up of the rail car and another group formed a queue to access the walkway (see Figure 3). When both groups were at their respective positions, a whistle signal was used to initiate the movement of participants. The test finished when all participants left the walkway. Then, participants were asked to go to another starting position for the next test (i.e. those who started from the walkway were asked to go to the rail car and vice versa). We took care to ensure that the position of the individuals within the group was randomly located (e.g. participants who were at front/back in one test in the walkway or in the rail car were randomly located to middle/front in next test). This was intended to minimise the cumulative learning behaviour of participants by introducing the randomness in their location. There were breaks every two tests to modify the rail car exit configurations (see Table 2). Therefore, participants had enough time to rest. Given this, learning and fatigue did not appear to be significant factors in any of the tests conducted. During the breaks participants were asked to take part in next tests. Some participants refused to take part in some tests as they felt unable to overcome height differentials of the rail car exit $(0.8 \mathrm{~m}$ and $1.2 \mathrm{~m})$. This is discussed in section 4.4 of this paper.

\begin{tabular}{|c|c|c|c|c|c|}
\hline \multirow{2}{*}{ Test } & \multicolumn{2}{|c|}{ Starting location of groups } & \multicolumn{3}{c|}{ Independent variables (exit configuration) } \\
\cline { 2 - 6 } & $\begin{array}{c}\boldsymbol{R} \text { Red } \\
\text { (\#participants) }\end{array}$ & $\begin{array}{c}\text { Yellow } \\
\text { (\#participants) }\end{array}$ & $\boldsymbol{W}_{\boldsymbol{h}}(\mathbf{m})$ & $\boldsymbol{W}_{\boldsymbol{v}}(\mathbf{m})$ & $\boldsymbol{h}(\mathbf{m})$ \\
\hline 1 & Rail car & Walkway & 1.2 & 0.8 & 0 \\
\hline 2 & Walkway & Rail car & 1.2 & 0.8 & 0 \\
\hline 3 & Rail car & Walkway & 1.2 & 1.2 & 0 \\
\hline 4 & Walkway & Rail car & 1.2 & 1.2 & 0 \\
\hline 5 & Walkway & Rail car & 0.8 & 0.8 & 0 \\
\hline 6 & Rail car & Walkway & 0.8 & 0.8 & 0 \\
\hline 7 & Walkway & Rail car & 0.8 & 1.2 & 0 \\
\hline 8 & Rail car & Walkway & 0.8 & 1.2 & 0 \\
\hline 9 & Rail car & Walkway & 0.8 & 0.8 & 0.8 \\
\hline 10 & Walkway & Rail car & 0.8 & 0.8 & 0.8 \\
\hline 11 & Rail car & Walkway & 1.2 & 0.8 & 0.8 \\
\hline 12 & Walkway & Rail car & 1.2 & 0.8 & 0.8 \\
\hline 13 & Walkway & Rail car & 1.2 & 1.2 & 1.2 \\
\hline 14 & Rail car & Walkway & 1.2 & 1.2 & 1.2 \\
\hline 15 & Walkway & Rail car & 0.8 & 1.2 & 1.2 \\
\hline 16 & Rail car & Walkway & 0.8 & 1.2 & 1.2 \\
\hline
\end{tabular}

Table 1. Tests conducted and values of the manipulated independent variables.

\begin{tabular}{|c|l|c|}
\hline Break & \multicolumn{1}{|c|}{ Description } & Time (min:s) \\
\hline 1 & After Test 2 to change the width of the rail car exit & $4: 32$ \\
\hline 2 & After Test 4 to change the widths of the rail car exit and the walkway & $22: 37$ \\
\hline 3 & After Test 6 to change the width of the rail car exit & $2: 31$ \\
\hline 4 & $\begin{array}{l}\text { After Test 8 to change the width and height of the rail car exit and } \\
\text { ask participants if they were willing to take part in the next test }\end{array}$ & $32: 30$ \\
\hline 5 & $\begin{array}{l}\text { After Test 10 to change width of the walkway and ask participants } \\
\text { if they were willing to participate }\end{array}$ & $13: 24$ \\
\hline 6 & $\begin{array}{l}\text { After test 12 to change the width and height of the rail car exit and } \\
\text { ask participants if they were willing to take part in the next test }\end{array}$ & $36: 30$ \\
\hline 7 & $\begin{array}{l}\text { After Test 14 to change the walkway width ask participants if they } \\
\text { were willing to take part in the next test }\end{array}$ & $13: 18$ \\
\hline
\end{tabular}

Table 2. Breaks during the experiment. 


\subsection{Measurement methods}

For the data collection 6 video-cameras were placed to obtain an overhead view of the rail car exit and the walkway. But only recordings from one video-camera were used for the data collection presented here. Video images were collected at a frequency of 29.97 frames/s. Video recordings were analysed manually frame by frame using the Avidemux 2.5.2 software. Two reference lines were previously defined to measure the merging flows (see Figure 1). The first reference line was the rail car exit and the second reference line was marked on the floor of the walkway $0.6 \mathrm{~m}$ before the rail car exit (see Figure 1). The merge area was a square/rectangle based on these reference lines. As Figure 4 shows, the software allows selecting/excluding regions to avoid "noise" in the manual measurements. The frame when all parts of individual's bodies had crossed the reference lines was noted and then transcribed into a spreadsheet.

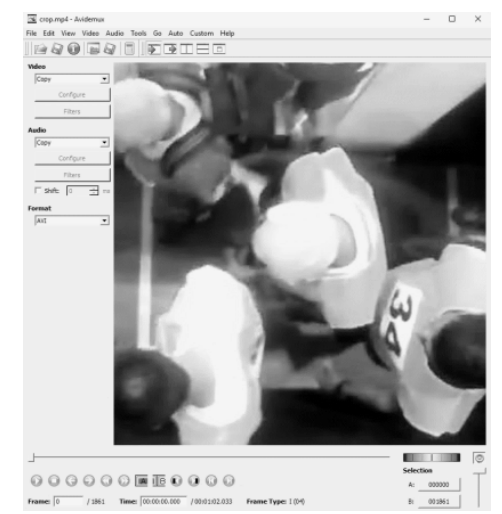

Fig.4. Specific region used for data processing.

To date various methods have been developed and introduced to measure the flow rates of evacuating persons. However, the use of a simple flow rate to represent exit performance tends to average personal hesitations and limitations in exiting performance, producing a simple representation of the actual passenger rail car exit flow (Galea et al. 2014). Although most of building evacuation models do not use stochastic variables to implement the flows, current rail car evacuation models consider exit time probability distributions rather than simple flow rates (Capote et al. 2012b; Galea et al. 2014). That is why the measurements were made according to the definition of a new random variable, namely the instantaneous specific flow $\left(\hat{F}_{s}\right)$ defined as the inverse of the time interval between two subjects that consecutively cross a point of reference $\left(\Delta t_{i, i-1}\right)$, divided by the effective width $\left(w_{e f}\right)$.

$$
\hat{F}_{S}=\frac{1}{\Delta t_{i, i-1} \cdot w_{e f}}
$$

As the specific flow $\left(F_{s}\right)$, the instantaneous specific flow $\left(\hat{F}_{s}\right)$ is the flow of evacuating persons past a point per unit of time per unit of effective width (Gwynne and Rosenbaum, 2015). Equation (1) shows how to measure the flow of evacuating persons without using the original expression $F_{s}$ $=S D$ where $S$ is the speed of movement and $D$ the density (Nelson and Mowrer, 2002). In other words, we used a different measurement method to obtain the flows. However, it should be note that $F_{s}$ and $\hat{F}_{s}$ have the same units (in per/s $\mathrm{m}$ ) as shown in Figure 5.

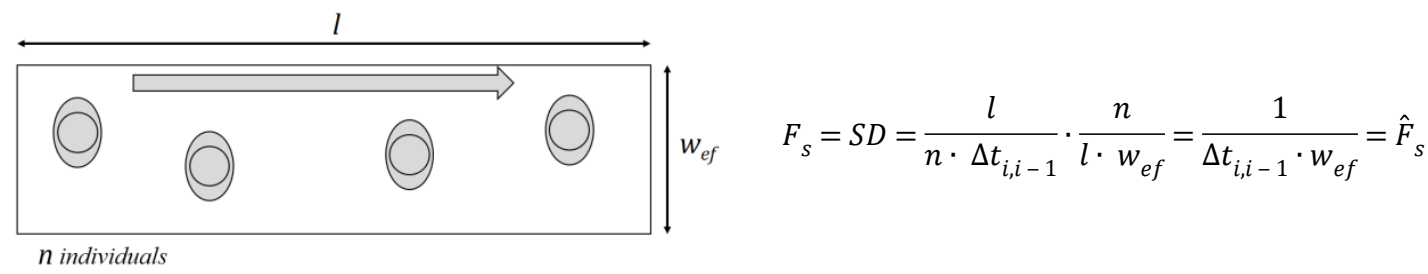


Fig. 5. Equality of $\hat{F}_{S}$ and $F_{S}$ units.

Note that the instantaneous specific flow can be easily defined by the proposed measurement method (i.e. the time intervals $\left(\Delta t_{i, i-1}\right)$ are just the difference between the frame of a participant and the frame of the next one who crosses the reference line). The advantage of using the instantaneous specific flow is the possibility to produce probability distributions instead of using constant/average values. The disadvantage is the very high values produced when time intervals between two subjects are too small. This problem may be addressed by excluding the extreme values (outliers) from data samples. The proposed methods for fences definition and elimination of outliers can be found in (Maronna and Yohai, 1995; Hubert and Vandervieren, 2008; Brys et al., 2004), because data samples of instantaneous flow often are skewed. In the present paper, we used the calculus of the medcouple, which is a robust measure of skewness introducing a correction to Tukey test (Turkey, 1977), based on the first and third quartiles and the IQR (interquartile range).

The data processing was focused on the occurrence of flows under different conditions. Therefore, we made a classification of the observed flows as follows:

$$
\hat{F}_{(X, T, h)_{i}}=\frac{F P S}{\left(F r_{(X, T, h)_{i}}-F r_{(X, T, h)_{i-1}}\right) \cdot W_{X}}
$$

Where:

$\hat{F}_{X_{i}} \quad$ - instantaneous specific flow of the $i$-th participant;

$X=H, V \quad$ - subscript to define the walkway flow (H- horizontal) or the rail car flow (Vvertical)

$T=C, U$ - subscript to define the flow under merging (C- constrained) or no merging conditions (U- unconstrained);

$h \quad$ - subscript to define the height differential of the rail car exit (in this study $0,0.8$ or $1.2 \mathrm{~m}$ );

$\mathrm{Fr}_{X_{i}} \quad$ - frame when the body of the $i$-th participant crosses the reference line;

$F r_{X_{i-1}} \quad$ - frame when the body of the previous participant crosses the reference line;

$W_{X} \quad$ - total width (in m). It can be $W_{V}$ (rail car exit width) or $W_{H}$ (walkway width);

FPS - video frame rate (in this study 29.97 frames/s).

Table 3 shows the different categories of flows considered.

\begin{tabular}{|c|l|l|c|}
\hline Flow & \multicolumn{1}{|c|}{ Class } & \multicolumn{1}{c|}{ Type } & h (m)* \\
\hline$\hat{F}_{H, U, 0}$ & Horizontal (from the walkway) & Unconstrained (no merging) & 0 \\
\hline$\hat{F}_{H, C, 0}$ & Horizontal (from the walkway) & Constrained (merging) & 0 \\
\hline$\hat{F}_{H, C, 0.8}$ & Horizontal (from the walkway) & Constrained (merging) & 0.8 \\
\hline$\hat{F}_{H, C, 1.2}$ & Horizontal (from the walkway) & Constrained (merging) & 1.2 \\
\hline$\hat{F}_{V, U, 0}$ & Vertical (from the rail car exit) & Unconstrained (no merging) & 0 \\
\hline$\hat{F}_{V, C, 0}$ & Vertical (from the rail car exit) & Constrained (merging) & 0 \\
\hline$\hat{F}_{V, U, 0.8}$ & Vertical (from the rail car exit) & Unconstrained (no merging) & 0.8 \\
\hline$\hat{F}_{V, C, 0.8}$ & Vertical (from the rail car exit) & Constrained (merging) & 0.8 \\
\hline$\hat{F}_{V, U, 1.2}$ & Vertical (from the rail car exit) & Unconstrained (no merging) & 1.2 \\
\hline$\hat{F}_{V, C, 1.2}$ & Vertical (from the rail car exit) & Constrained (merging) & 1.2 \\
\hline${ }^{*}$ Height differential of rail car exit & & \\
\hline
\end{tabular}

Table 3. Flow categories for the analysis.

According to this classification, the data for the repeated tests were combined, producing a set of 
10 flow samples for the analysis:

$N_{S}=\left\{n_{H, U, 0}, n_{H, C, 0^{\prime}}, n_{H, C, 0.8}, n_{H, C, 1.2^{2}}, n_{V, U, 0^{0}}, n_{V, C, 0^{\prime}}, n_{V, U, 0.8^{\prime}}, n_{V, C, 0.8}, n_{V, U, 1.2}, n_{V, C, 1.2}\right\}$

Where:

$N_{S}$ - The set of flow samples in different conditions;

$n_{X, T, h}$ - sample of flows $X$-th (H- horizontal or V- vertical), $T$-th (C - Constrained or U unconstrained) and $h$ (heights differences of the rail car exit of $0,0.8$ or $1.2 \mathrm{~m}$ ).

\section{Results}

\subsection{Flow distributions and hypothesis testing}

Table 4 shows the statistical parameters of the instantaneous specific flow distributions. The data are presented independently, given the different possible uses of this data. Mean values in table 4 could be assumed as the specific flows. The observed flows varied depending on the occurrence of merging and the height differential of the rail car exit. This leads to formulate the following hypotheses:

Hypothesis 1: People in the tunnel walkway affected the train exit flow. Hypothesis 2: People exiting the rail car affected the tunnel walkway flow. Hypothesis 3: Height differential affected the rail car exit flow.

These hypotheses were tested using the Mann-Whitney-Wilcoxon (MWW) (Mann and Whitney, 1947; Fay et al, 2010), the Two-sample Kolmogorov-Smirnov (K-S) test (Stephens, 1974) and the Welch's $t$-test (Welch) (Ruxton, 2006).

\begin{tabular}{|c|c|c|c|c|c|c|}
\hline Flow & \# & $\begin{array}{c}\text { Mean } \\
\text { [per/s m] }\end{array}$ & $\underset{[\text { S.Der/s m] }}{\text { S.D. }}$ & $\begin{array}{c}95 \% \text { half } \\
\text { confidence } \\
\text { interval }[\text { per/s m] }\end{array}$ & Skewness & Kurtosis \\
\hline$\hat{F}_{H, U, 0}$ & 87 & 1.51 & 0.10 & 0.46 & 0.238 & -0.444 \\
\hline$\hat{F}_{H, C, 0}$ & 228 & 1.44 & 0.15 & 1.15 & 2.398 & 6.303 \\
\hline$\hat{F}_{H, C, 0.8}$ & 126 & 1.09 & 0.11 & 0.62 & 2.117 & 6.082 \\
\hline$\hat{F}_{H, C, 1.2}$ & 104 & 0.95 & 0.10 & 0.52 & 1.084 & 1.304 \\
\hline$\hat{F}_{V, U, 0}$ & 55 & 2.59 & 0.50 & 1.84 & 2.185 & 4.066 \\
\hline$\hat{F}_{V, C, 0}$ & 217 & 1.71 & 0.21 & 1.59 & 2.366 & 5.895 \\
\hline$\hat{F}_{V, U, 0.8}$ & 30 & 1.17 & 0.11 & 0.29 & 0.206 & -0.732 \\
\hline$\hat{F}_{V, C, 0.8}$ & 100 & 0.78 & 0.05 & 0.26 & 1.154 & 2.352 \\
\hline$\hat{F}_{V, U, 1.2}$ & 13 & 0.90 & 0.19 & 0.32 & 1.248 & 0.501 \\
\hline$\hat{F}_{V, C, 1.2}$ & 87 & 0.51 & 0.04 & 0.21 & 1.145 & 1.371 \\
\hline
\end{tabular}

Table 4. Main parameters of instantaneous specific flow distributions.

Tables 5-7 show the results of the statistical hypotheses (level of significance $\alpha=0.05$ ). As expected, the presence of people in the walkway affected the rail car exit flow $\left(\mathrm{H}_{0}\right.$ rejected using MWW, K-S and Welch statistical tests). In addition, rail car exit flow affected the walkway flow $\left(\mathrm{H}_{0}\right.$ rejected using MWW, K-S and Welch tests). Furthermore, results in Table 7 show that the height differential of the rail car exit affected the exiting process $\left(\mathrm{H}_{0}\right.$ rejected using MWW, K-S and Welch tests).

\begin{tabular}{|c|c|c|c|c|c|c|}
\hline \multirow{2}{*}{ Pair of samples } & \multicolumn{2}{|c|}{ MWW } & \multicolumn{2}{c|}{ K-S } & \multicolumn{2}{c|}{ Welch } \\
\cline { 2 - 6 } & Statistics & $\mathbf{H}_{\mathbf{0}}$ & Statistics & $\mathbf{H}_{\mathbf{0}}$ & Statistics & $\mathbf{H}_{\mathbf{0}}$ \\
\hline
\end{tabular}




\begin{tabular}{|c|c|c|l|c|l|c|c|}
\hline \multicolumn{2}{|c|}{} & comparison & & comparison & & comparison & \\
\hline$n_{V, U, 0}$ & $n_{V, C, 0}$ & $5.91 \geq 1.96$ & Rejected & $0.57>0.21$ & Rejected & $3.23 \geq 1.99$ & Rejected \\
\hline$n_{V, U, 0.8}$ & $n_{V, C, 0.8}$ & $5.21 \geq 1.96$ & Rejected & $0.53>0.28$ & Rejected & $6.31 \geq 2.02$ & Rejected \\
\hline$n_{V, U, 1.2}$ & $n_{V, C, 1.2}$ & $4.51 \geq 1.96$ & Rejected & $0.67>0.40$ & Rejected & $4.13 \geq 2.16$ & Rejected \\
\hline
\end{tabular}

Table 5. Statistical tests results when comparing constrained and unconstrained flows from the rail car exit. Hypothesis 1.

\begin{tabular}{|c|c|c|c|c|c|c|c|}
\hline \multirow{2}{*}{ Pair of samples } & \multicolumn{2}{|c|}{ MWW } & \multicolumn{2}{c|}{ K-S } & \multicolumn{2}{c|}{ Welch } \\
\cline { 2 - 8 } & & $\begin{array}{c}\text { Statistics } \\
\text { comparison }\end{array}$ & $\mathbf{H}_{\mathbf{0}}$ & $\begin{array}{c}\text { Statistics } \\
\text { comparison }\end{array}$ & $\mathbf{H}_{\mathbf{0}}$ & $\begin{array}{c}\text { Statistics } \\
\text { comparison }\end{array}$ & $\mathbf{H}_{\mathbf{0}}$ \\
\hline$n_{H, U, 0}$ & $n_{H, C, 0}$ & $4.15 \geq 1.96$ & Rejected & $0.32>0.17$ & Rejected & $6.25 \geq 1.96$ & Rejected \\
\hline$n_{H, U, 0}$ & $n_{H, C, 0.8}$ & $6.87 \geq 1.96$ & Rejected & $0.47>0.19$ & Rejected & $8.59 \geq 1.96$ & Rejected \\
\hline$n_{H, U, 0}$ & $n_{H, C, 1.2}$ & $7.42 \geq 1.96$ & Rejected & $0.50>0.20$ & Rejected & $7.65 \geq 1.96$ & Rejected \\
\hline
\end{tabular}

Table 6. Statistical tests results when comparing constrained and unconstrained walkway flows.

Hypothesis 2.

\begin{tabular}{|c|c|c|c|c|c|c|c|}
\hline \multirow{2}{*}{ Pair of samples } & \multicolumn{2}{|c|}{ MWW } & \multicolumn{2}{c|}{ K-S } & \multicolumn{2}{c|}{ Welch } \\
\cline { 3 - 8 } & $\begin{array}{c}\text { Statistics } \\
\text { comparison }\end{array}$ & $\mathbf{H}_{\mathbf{0}}$ & $\begin{array}{c}\text { Statistics } \\
\text { comparison }\end{array}$ & $\mathbf{H}_{\mathbf{0}}$ & $\begin{array}{c}\text { Statistics } \\
\text { comparison }\end{array}$ & $\mathbf{H}_{\mathbf{0}}$ \\
\hline$n_{V, C, 0}$ & $n_{V, C, 0.8}$ & $7.32 \geq 1.96$ & Rejected & $0.40>0.16$ & Rejected & $8.29 \geq 1.96$ & Rejected \\
\hline$n_{V, C, 0}$ & $n_{V, C, 1.2}$ & $11.71 \geq 1.96$ & Rejected & $0.69>0.17$ & Rejected & $10.82 \geq 1.96$ & Rejected \\
\hline$n_{V, C, 0.8}$ & $n_{V, C, 1.2}$ & $7.40 \geq 1.96$ & Rejected & $0.50>0.20$ & Rejected & $7.81 \geq 1.96$ & Rejected \\
\hline$n_{V, U, 0}$ & $n_{V, U, 0.8}$ & $5.98 \geq 1.96$ & Rejected & $0.65>0.31$ & Rejected & $5.54 \geq 2.00$ & Rejected \\
\hline$n_{V, U, 0}$ & $n_{V, U, 1.2}$ & $5.01 \geq 1.96$ & Rejected & $0.79>0.42$ & Rejected & $6.32 \geq 2.00$ & Rejected \\
\hline$n_{V, U, 0.8}$ & $n_{V, U, 1.2}$ & $2.63 \geq 1.96$ & Rejected & $0.49>0.45$ & Rejected & $2.47 \geq 2.08$ & Rejected \\
\hline
\end{tabular}

Table 7. Statistical tests results when comparing flows of different height differentials of the rail car exit. Hypothesis 3.

\subsection{Unconstrained vs constrained flows}

From the statistical tests of section 4.1, it is possible to say that walkway flow and rail car exit flow decreased due to the occurrence of merging. To measure this, we introduced the coefficient of constraint defined as the proportion of reduction of the mean of unconstrained flow (no merging) when compared with the mean of constrained flow (merging):

$$
k_{C(X, h)}=\frac{M\left(\hat{F}_{(X, C, h)}\right)}{M\left(\hat{F}_{(X, U, h)}\right)}
$$

Where:

$k_{C(X, h)}$ - coefficient of constraint for flows $X(\mathrm{H}$ - horizontal or $\mathrm{V}$ - vertical) and with $\mathrm{h}$ (the height differential of the rail car exit in $\mathrm{m})$;

$M(Z)$ - mean (expected) value of $Z$ variable.

Subscripts were previously defined in equation (2).

The confidence interval for $k_{C(X, h)}$ can be calculated by:

$\operatorname{Pr}_{k_{C(X, h)}}\left(\left.k_{C(X, h)}\right|_{\min }<k_{C(X, h)}<\left.k_{C(X, h)}\right|_{\max }\right)=P_{k}$

Where:

$P_{k}$ - confidence interval for $k_{C(X, h)}$. 
$\left.k_{C(X, h)}\right|_{\min }=\frac{M\left(\hat{F}_{(X, C, h)}\right)-\Delta M\left(\hat{F}_{(X, C, h)}\right)}{M\left(\hat{F}_{(X, U, h)}\right)+\Delta M\left(\hat{F}_{(X, U, h)}\right)}$

$\left.k_{C(X, h)}\right|_{\text {max }}= \begin{cases}\frac{M\left(\hat{F}_{(X, C, h)}\right)+\Delta M\left(\hat{F}_{(X, C, h)}\right)}{M\left(\hat{F}_{(X, U, h)}\right)-\Delta M\left(\hat{F}_{(X, U, h)}\right)} & \text { if } \frac{M\left(\hat{F}_{(X, C, h)}\right)+\Delta M\left(\hat{F}_{(X, C, h)}\right)}{M\left(\hat{F}_{(X, U, h}\right)-\Delta M\left(\hat{F}_{(X, U, h)}\right)} \leq 1 \\ 1 & \text { if } \frac{M\left(\hat{F}_{(X, C, h)}\right)+\Delta M\left(\hat{F}_{(X, C, h)}\right)}{M\left(\hat{F}_{(X, U, h}\right)-\Delta M\left(\hat{F}_{(X, U, h)}\right)}>1\end{cases}$

$\Delta M(Z)$ - half of confidence interval of the mean of $Z$; being the variable $Z \hat{F}_{(X, C, h)}$ or $\hat{F}_{(X, U, h)}$.

$$
\begin{gathered}
P_{k}=\operatorname{Pr}\left(k_{C(X, h)}>\left.k_{C(X, h)}\right|_{\min }\right) \times \operatorname{Pr}\left(k_{C(X, h)}<\left.k_{C(X, h)}\right|_{\text {max }}\right) \\
\operatorname{Pr}\left(k_{C(X, h)}>\left.k_{C(X, h)}\right|_{\min }\right)=\operatorname{Pr}\left(k_{C(X, h)}<\left.k_{C(X, h)}\right|_{\text {max }}\right)=\operatorname{Pr} \\
\left(M\left(\hat{F}_{(X, C, h)}\right)>\left(M\left(\hat{F}_{(X, C, h)}\right)-\Delta M\left(\hat{F}_{(X, C, h)}\right)\right)\right) \times \operatorname{Pr}\left(M\left(\hat{F}_{(X, C, h)}\right)<\left(M\left(\hat{F}_{(X, C, h)}\right)+\Delta M\left(\hat{F}_{(X, C, h)}\right)\right)\right)
\end{gathered}
$$

As known:

$\operatorname{Pr}\left(M\left(\hat{F}_{(X, C, h)}\right)<\left(M\left(\hat{F}_{(X, C, h)}\right)+\Delta M\left(\hat{F}_{(X, C, h)}\right)\right)\right)=1-\propto / 2$

$\propto \quad$ - significance level of calculated mean confidence interval.

Then, from (8) - (10), if $\alpha=0.05, P_{k}=0.9037$

Table 8 shows the coefficients of constraint produced. It is apparent that the rail car exit flow was more affected than the walkway flow when merged. What is interesting about the data in Table 8 is the impact produced by the height differential (h). While this had a slightly influence on the rail car exit flow, the coefficients of constrain of the walkway flow decreased by $23 \%$ when comparing $\mathrm{h}=0$ with $\mathrm{h}=0.8$ and by $32 \%$ when comparing $\mathrm{h}=0$ with $\mathrm{h}=1.2$. This could be due to deference behaviours of walkway participants.

\begin{tabular}{|c|c|c|c|c|}
\hline Flow & $\mathbf{h}(\mathbf{m})^{*}$ & $\boldsymbol{k}_{\boldsymbol{C}(\boldsymbol{X}, \boldsymbol{h})}$ & $\left.\boldsymbol{k}_{\boldsymbol{C}(\boldsymbol{X}, \boldsymbol{h})}\right|_{\min }$ & $\left.\boldsymbol{k}_{\boldsymbol{C}(\boldsymbol{X}, \boldsymbol{h})}\right|_{\max }$ \\
\hline \multirow{3}{*}{ Rail car exit } & 0 & 0.66 & 0.48 & 0.92 \\
\cline { 2 - 5 } & 0.8 & 0.67 & 0.57 & 0.79 \\
\cline { 2 - 5 } & 1.2 & 0.57 & 0.43 & 0.78 \\
\hline \multirow{3}{*}{ Walkway } & 0 & 0.95 & 0.80 & 1.00 \\
\cline { 2 - 5 } & 0.8 & 0.72 & 0.61 & 0.85 \\
\cline { 2 - 5 } & 1.2 & 0.63 & 0.53 & 0.74 \\
\hline *Height differential of rail car exit
\end{tabular}

Table 8. Coefficients of constraint and confidence bounds.

\subsection{Interdependence of flows when merge}

This section explores the interdependence of flows when merged. We assumed that the mean of the rail car exit flow and the mean of the walkway flow were mutually dependent. The data analysis consisted of transforming the independent flow samples into paired samples. Hence, we explored a novel way of data clustering: 1) Clustering Type I where clusters are defined as groups of participants who interact each other during the merging process and Clustering Type II where clusters are defined as time intervals during the merging process. 
Due to clustering is not an automatic task but an iterative process, we selected different groups of participants for Clustering Type I (6, 8 and 10 participants) and time intervals for Clustering Type II $(5,7.5$ and $10 \mathrm{~s})$. This was based on a detailed analysis of video recordings (frame by frame). Then, paired samples were plotted and analysed to estimate the relationship between the variables (walkway flow and rail car exit flow). The ordinary less-square linear regression through the origin was employed (Eisenhauer, 2003). When the walkway flow is zero the rail car exit flow should be zero as well, due to the absence of merging.

Figures 6-11 show the interdependence of flows when merged. The straight line in figures, with a slope equal to 1 , was used as a reference of no reciprocal influence (i.e. both flows have the same value). This reference line also represents a merging ratio of 50:50. The relationship between the flows varied considerably during the merge period. Data points above the reference line were rail car exit bias while data points below the reference line were walkway bias. As expected, data clustering affected the results. Despite this, the slopes of the regression lines (dashed lines) were below the reference line (straight line) in all cases. The lower the slope of the regression line the higher the priority of the walkway flow.

Tables 9 and 10 display the slopes of the regression lines, the correlation coefficients and the merging ratios produced. The regression lines fit data well with values of the correlation coefficients between 0.67 and 0.99 . Thus, it is argued that the slopes of the lines are valid to describe the relationship between flows. The bias in the evacuation was slightly in favour of the walkway when there was not height differential. In this case, for $\mathrm{h}=0$, the slopes of the regression lines ranged from 0.87 to 0.97 in Clustering Type I and from 0.83 to 0.96 in Clustering Type II. Contrary to expectations, we found a moderate dominance of walkway flow with a height differential in the rail car exit of $h=0.8$. The higher variation was found in this case with slopes of the regression lines ranged from 0.79 to 0.92 in Clustering Type I while Clustering Type II produced slopes from 0.81 to 0.84 . Less variation in the slopes of the regression lines was observed for $\mathrm{h}=1.2$ with lower values ranged from 0.53 to 0.65 and from 0.53 to 0.63 in Clustering Type I and II respectively. Based on this, it is possible to say that, in this case, walkway participants took a clear priority over the train participants.

Groups of 6 participants

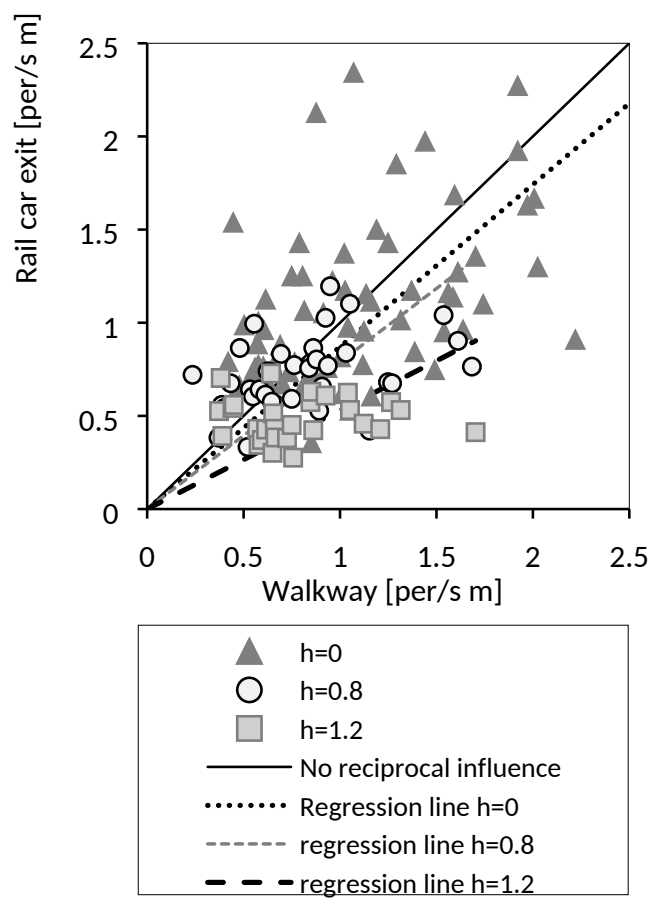

Fig. 6. Correlation between flows. Clustering Type
Time intervals of $5 \mathrm{~s}$

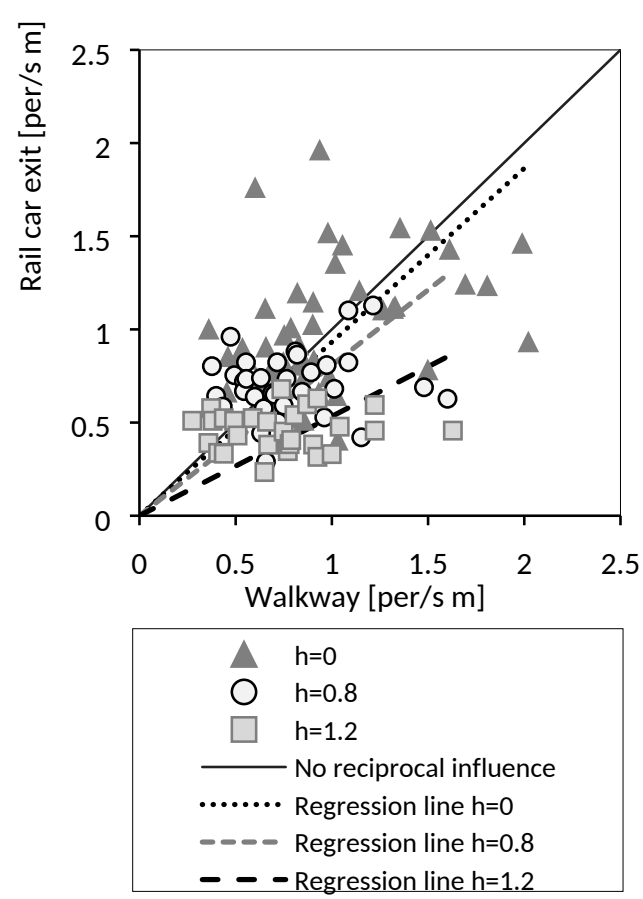

Fig. 7. Correlation between flows. Clustering 
I: groups of 6 participants.

\section{Groups of 8 participants}
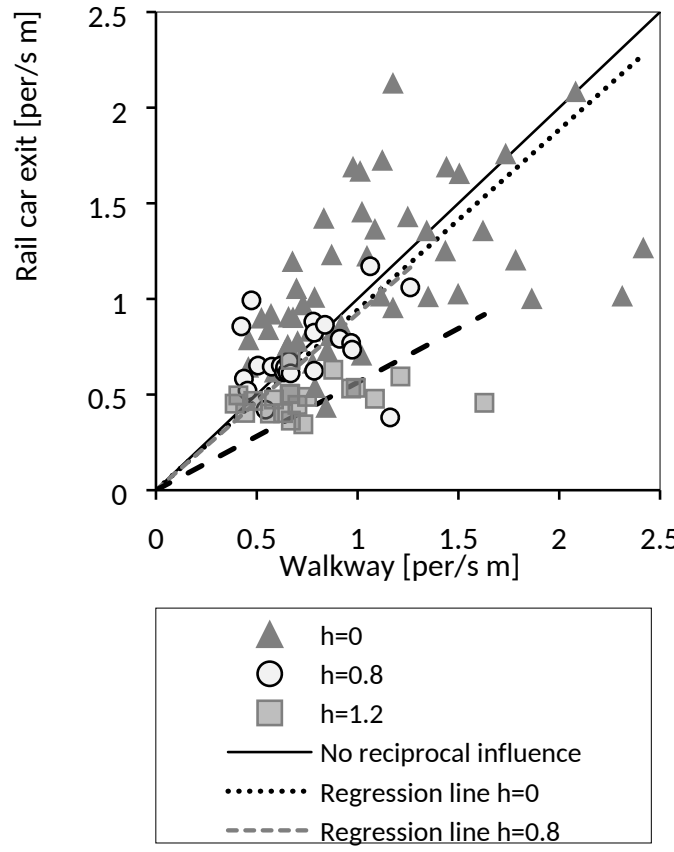

Fig. 8. Correlation between flows. Clustering

Type I: groups of 8 participants.

Groups of 10 participants

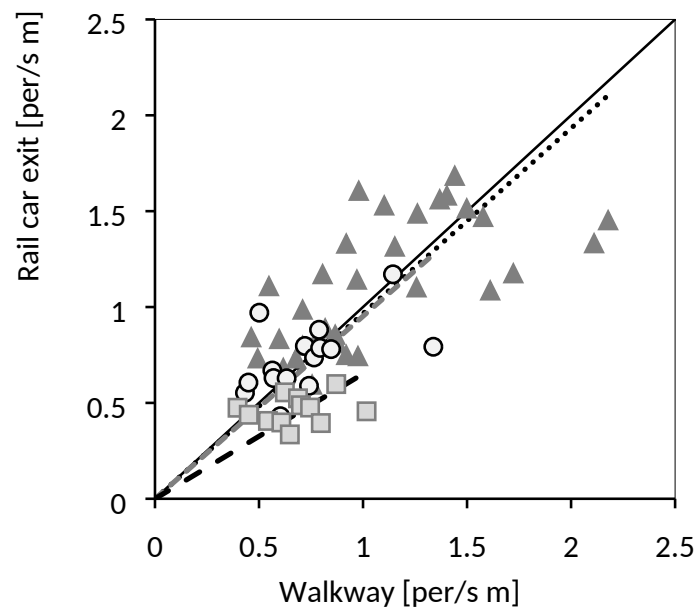

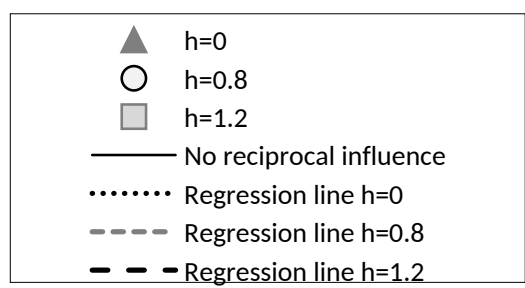

Fig. 10. Correlation between flows. Clustering Type I: groups of 10 participants.
Type II: time intervals of $5 \mathrm{~s}$.

Time intervals of $7.5 \mathrm{~s}$
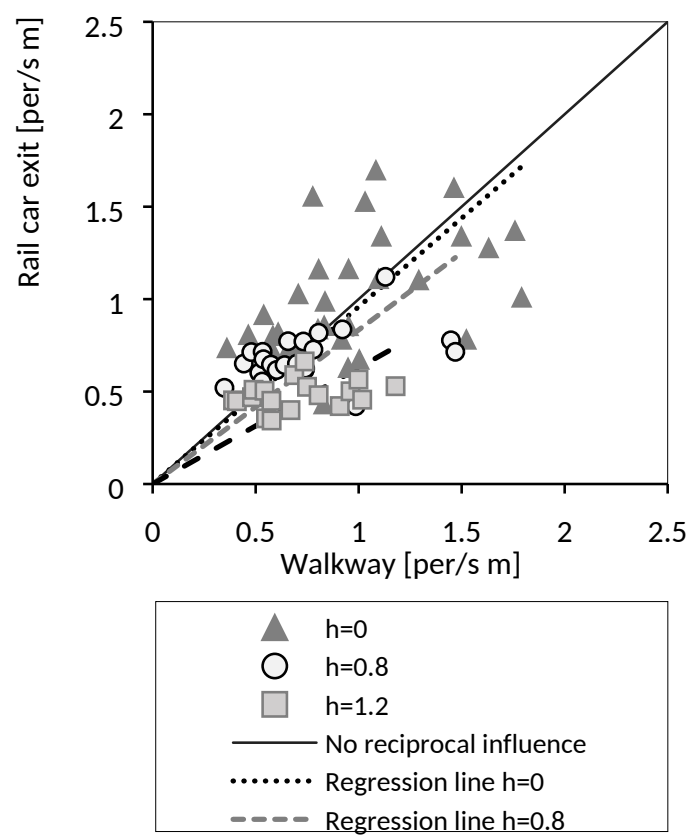

Fig. 9. Correlation between flows. Clustering Type II: time intervals of $7.5 \mathrm{~s}$.

Time intervals of $10 \mathrm{~s}$
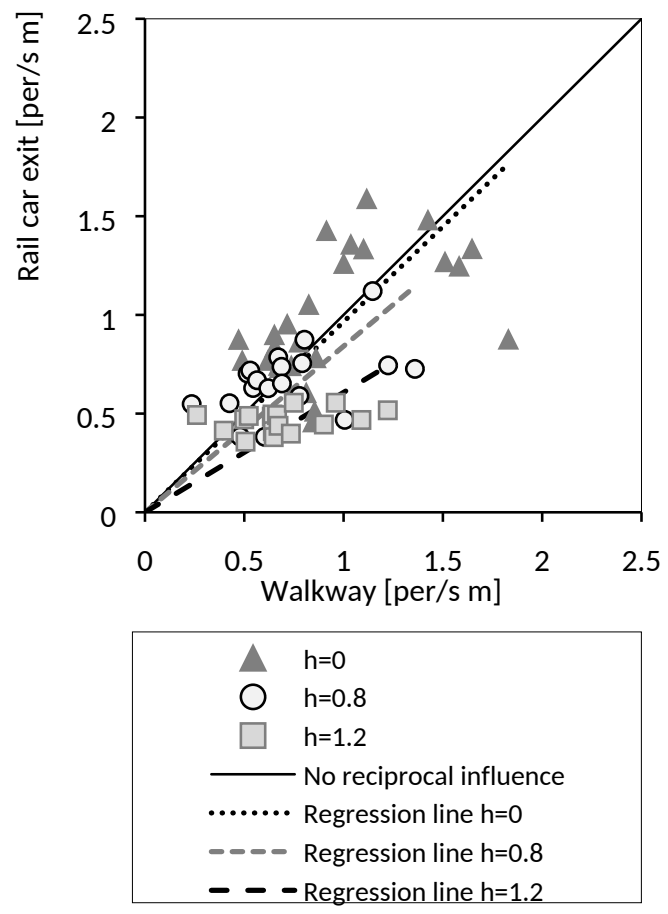

Fig. 11. Correlation between flows. Clustering Type II: time intervals of $10 \mathrm{~s}$.

The merging ratios in Tables 9 and 10 also provide an overview of the merging patterns through the quantitative measurement of the preference between the walkway flow over the rail car exit flow. The average merging ratios (walkway/rail car exit) derived from this analysis were 53:47 for $\mathrm{h}=0,58: 42$ for $\mathrm{h}=0.8$ and $71: 29$ for $\mathrm{h}=1.2$. 


\begin{tabular}{|c|c|c|c|c|c|}
\hline $\begin{array}{c}\text { Clustering } \\
\text { Type I }\end{array}$ & $\#$ & $\mathbf{h}(\mathbf{m}) *$ & Slope & $\begin{array}{c}\text { Correlation } \\
\text { coefficient (R) }\end{array}$ & $\begin{array}{c}\text { Merging ratio } \\
\text { walkway:rail car exit }\end{array}$ \\
\hline \multirow{4}{*}{6 per } & 70 & 0 & 0.87 & 0.99 & $57: 43$ \\
\cline { 2 - 6 } & 35 & 0.8 & 0.79 & 0.74 & $61: 39$ \\
\cline { 2 - 6 } & 28 & 1.2 & 0.53 & 0.74 & $74: 26$ \\
\hline \multirow{3}{*}{8 per } & 49 & 0 & 0.94 & 0.89 & $53: 47$ \\
\cline { 2 - 6 } & 23 & 0.8 & 0.92 & 0.92 & $54: 46$ \\
\cline { 2 - 6 } & 20 & 1.2 & 0.56 & 0.67 & $72: 28$ \\
\hline \multirow{3}{*}{10 per } & 33 & 0 & 0.97 & 0.81 & $52: 48$ \\
\cline { 2 - 6 } & 15 & 0.8 & 0.80 & 0.86 & $60: 40$ \\
\cline { 2 - 6 } & 12 & 1.2 & 0.65 & 0.87 & $68: 32$ \\
\hline *Height differential of rail car exit \\
Table 9. Slopes, correlation coefficients and associates merging flows for Clustering Type I.
\end{tabular}

\begin{tabular}{|c|c|c|c|c|c|}
\hline $\begin{array}{c}\text { Clustering } \\
\text { Type II }\end{array}$ & $\#$ & $\mathbf{h}(\mathbf{m}) *$ & Slope & $\begin{array}{c}\text { Correlation } \\
\text { coefficient (R) }\end{array}$ & $\begin{array}{c}\text { Merging ratio } \\
\text { walkway:rail car exit }\end{array}$ \\
\hline \multirow{3}{*}{$5 \mathrm{~s}$} & 47 & 0 & 0.93 & 0.91 & $54: 46$ \\
\cline { 2 - 6 } & 34 & 0.8 & 0.81 & 0.77 & $60: 40$ \\
\cline { 2 - 6 } & 28 & 1.2 & 0.53 & 0.71 & $74: 26$ \\
\hline \multirow{4}{*}{$7.5 \mathrm{~s}$} & 32 & 0 & 0.96 & 0.89 & $52: 48$ \\
\cline { 2 - 6 } & 22 & 0.8 & 0.83 & 0.68 & $59: 41$ \\
\cline { 2 - 6 } & 18 & 1.2 & 0.63 & 0.74 & $69: 31$ \\
\hline \multirow{3}{*}{$10 \mathrm{~s}$} & 25 & 0 & 0.96 & 0.86 & $52: 48$ \\
\cline { 2 - 6 } & 19 & 0.8 & 0.84 & 0.80 & $58: 42$ \\
\cline { 2 - 6 } & 17 & 1.2 & 0.61 & 0.68 & $70: 30$ \\
\hline
\end{tabular}

*Height differential of rail car exit

Table 10. Slopes, correlation coefficients and associates merging flows for Clustering Type II.

\subsection{Behaviour of participants}

A proportion of elder people was used in the experiment. Therefore, the major concern was the height differential of the rail car exit. Participants were asked to participate before every change in the exit configuration due to ethical issues. Table 11 shows the number of participants that quit the experiment. What is interesting in the data is that participants gradually refused to take part in the tests. Some felt unable to overcome height differential in advance while others gave up before repeating. They were asked and they explained that they did their best (i.e. as if they were in a real situation).

\begin{tabular}{|c|c|c|c|c|}
\hline \multirow{2}{*}{ Test } & \multirow{2}{*}{$\boldsymbol{h}_{\boldsymbol{v}}(\mathrm{m})$} & \multirow{2}{*}{ Group } & \multicolumn{2}{|c|}{ Participants who refused } \\
\cline { 4 - 5 } & & $\#$ & $\mathbf{\%}$ \\
\hline Test 9 & 0.8 & \multirow{4}{*}{ Red } & 3 & 7.69 \\
\hline Test 11 & 0.8 & 4 & 10.26 \\
\hline Test 14 & 1.2 & & 9 & 23.08 \\
\hline Test 16 & 1.2 & & 11 & 28.21 \\
\hline & & & & \\
\hline Test 10 & 0.8 & \multirow{4}{*}{ Yellow } & 1 & 2.63 \\
\hline Test 12 & 0.8 & 3 & 7.89 \\
\hline Test 13 & 1.2 & & 10 & 26.32 \\
\hline Test 15 & 1.2 & & 12 & 31.58 \\
\hline
\end{tabular}

Table 11. Number of participants who quit the experiment. 
Observations from video recordings complement the quantitative analysis described in sections 4.1, 4.2 and 4.3. In exit configurations with height differentials of 0.8 and $1.2 \mathrm{~m}$ participants were observed using different exiting strategies (Oswald et al., 2008; 2011): "jump" directly to the walkway without any support, "side" supporting by hands on train floor, shoulder and/or hands from others and "sit" down on the floor level inside the rail car. Figure 12 shows the percentage of the three exiting strategies displayed by participants. Results show a direct relationship between the height differential of the rail car exit and the exiting strategy. The percentage of participants who used a "sit" exiting strategy increased by $22 \%$ while "side" and "jump" exiting strategies decreased by $11 \%$ when the height differential of the rail car exit changed from $h=0.8 \mathrm{~m}$ to $\mathrm{h}=$ $1.2 \mathrm{~m}$.

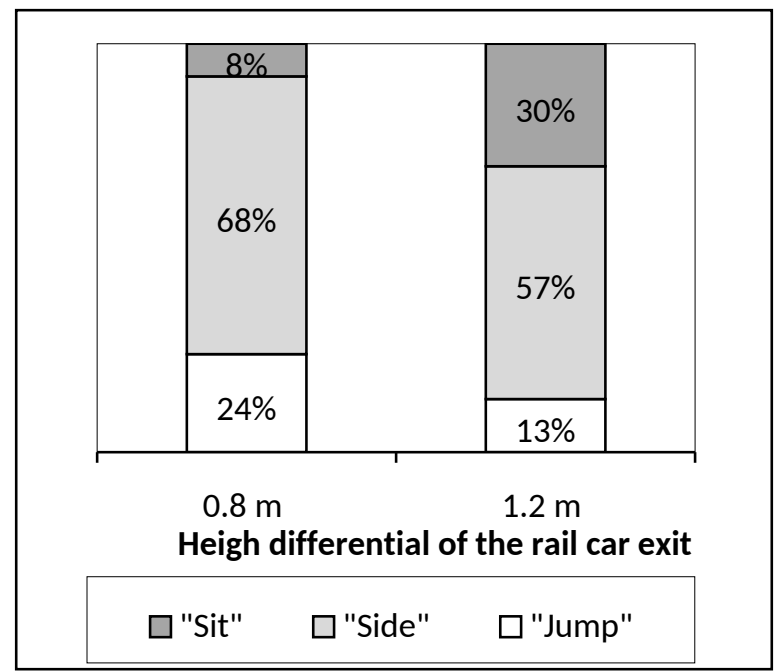

Fig. 12. Exiting strategies used by participants to negotiate the height differential of the rail car exit.

In addition to the exiting strategies, participants were observed waiting until there was enough space for them to exit into the walkway. This was combined with deference behaviours of people in the walkway. Some participants slowed down to let one or more participants out of the rail car. By $11 \%$ of participants were observed interrupting the continuous movement to help those entering from the rail car (see Figure 13). In one instance, a male participant helped 6 female participants to overcome the exit. We observed 38 "helpers" and " 41 "assisted" participants. While the percentage of "helpers" was slightly in favour of male participants (55\% male and 45 $\%$ female "helpers"), the majority of "assisted" participants were female (by $80 \%$ ). Nevertheless, the higher frequency was obtained for female participants helped by female participants (FemaleFemale $=47.06 \%$; Female-Male $=8.82 \%$; Male-Female $=29.41 \%$; Male-Male $=14.71 \%$ )
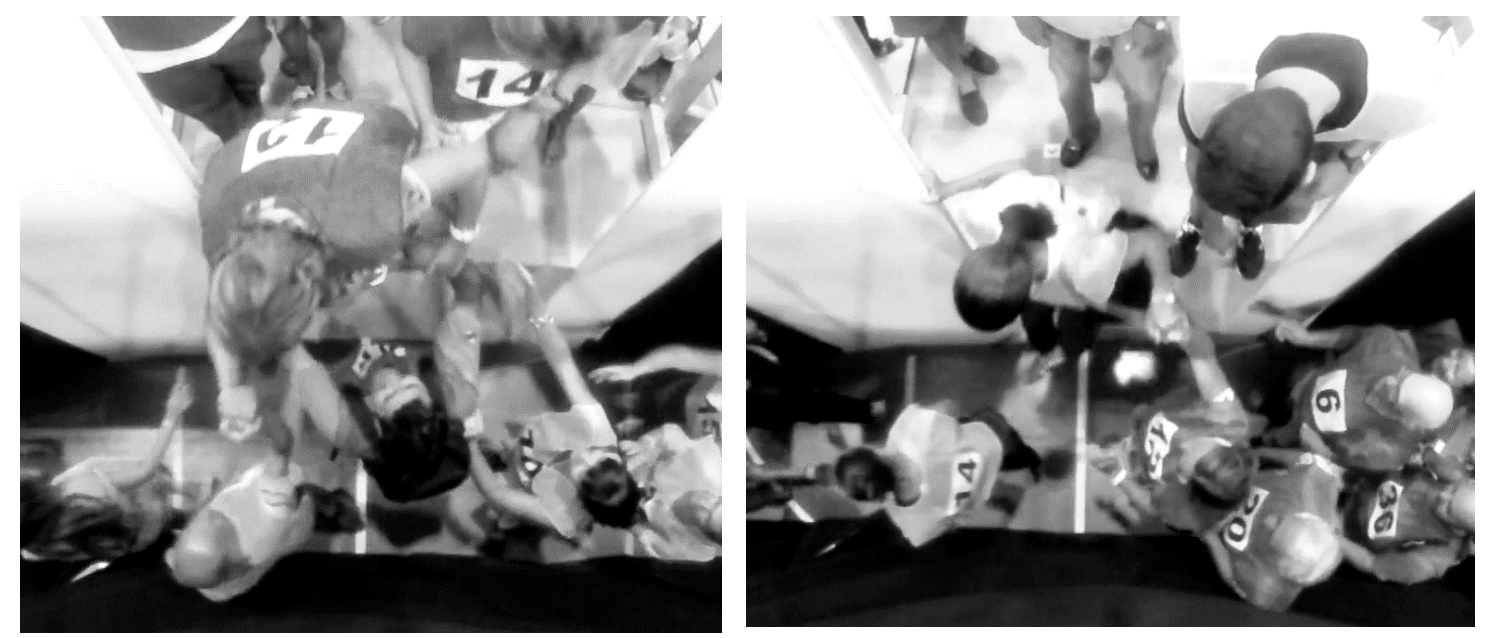
Fig.13. Participants helping others to negotiate the height differential of the rail car exit.

\section{Discussion}

The understanding of merging flows during evacuation in rail tunnels has important implications for people safety. Nevertheless, in reviewing the literature, no data was found on this issue. The focus of this experimental research was a primary performance factor i.e. the analysis of merging flows in different rail car exit configurations. A mock-up of a rail car exit and a lateral walkway were used in the experiment. A representative sample of future rail transport users was used involving 77 participants with a reasonable proportion of senior subjects (by $29 \%>60$ years).

Flow rates have been using to describe the number of people that cross a point in the exit route in a given time (Gwynne and Rosenbaum, 2015). The use of flow rates tends to average personal hesitations and limitations in rail car exit flow (Galea et al., 2014). The flow is a random variable that depends on passengers (abilities, behaviour, baggage), design (exit, walkway) and how they behave in response to it (Capote et al., 2012a; Gwynne et al., 2009). It is also important to keep in mind that, rather than individual movement values and individual result, simulation models are now requiring distributions to produce probabilities of outcomes (Cuesta et al., 2016). In fact, current evacuation models for passenger trains use distributions to represent the exiting performances of passengers (Capote et al. 2012; Galea et al. 2014). The novel contribution of our research is the use of flow distributions rather than average values within arbitrary time periods. The proposed new random variable (the instantaneous specific flow) derived from a straightforward way of measuring the flows (i.e. the time intervals between participants passing a reference line). The collected flows were classified and combined to produce a set of 10 flow samples for the statistical analysis.

As confirmed, the occurrence of merging could have a negative effect during a train evacuation inside a tunnel. Flows decreased when merge. The presence of people in the merging area and the height differential of the train exit affected both the walkway flow and the rail car exit flow. A coefficient of constraint was proposed to quantify the impact of merging conditions on flows. By looking at each flow independently, it is apparent that the walkway flow was less affected than the rail car exit flow when merge. Regression analysis was used to predict the interdependence between walkway flow and rail car exit flow. This was based on the idea that the means of both flows are mutually dependent. Flow samples were transformed into paired samples by using a novel clustering approach (clusters defined by groups of participants and by time intervals). From the results it seems that in this configuration, i.e. a walkway with a single rail car exit (at different height differentials), walkway evacuees took priority over rail car evacuees, although the extent to which this occurs was variable. The bias in the evacuation was slightly in favour of the walkway when there was not height differential of the rail car exit. Contrary to expectations, we found a moderate dominance of walkway flow with a height differential of the rail car exit of $0.8 \mathrm{~m}$. However, there was a clear dominance of the walkway flow over the rail car exit flow when the rail car exit was $1.2 \mathrm{~m}$ in height.

Overall, these results suggest that the higher the height differential of the rail car exit the more dominance of the walkway flow. In such conditions, participants waited until there was enough space in the walkway for them to exit the train and used different exiting strategies ("jump", "side" and "sit") to negotiate the height differential. This considerably reduced the rail car exit flow. The "side" exiting strategy was the most used by participants while "jump" and "sit" exiting strategies decreased and increased respectively when the height differential increased from 0.8 to $1.2 \mathrm{~m}$.

Deference behaviours of walkway participants were observed, particularly in evacuations with higher height differentials in the rail car exit. They stopped to help those entering from the rail car by given their hands and/or using their bodies as support. Previous studies suggested that gender may be linked to deference behaviour (Boyce et al., 2012; Melly, et al., 2009). Contrary 
to expectations, this study did not find gender playing a role in deference behaviour (prevalence of male-helping-female).

One of the issues that emerges from this study is associated with the ability of senior (or disabled) passengers to exit the train at a given height differential. In the wors case, by $7.69 \%$ and $26.32 \%$ of participants refushed to take part in tests with height differentials of 0.8 and $1.2 \mathrm{~m}$ respectively (problably the ones who have more difficulties in passing a large height differential). This has important implications for rail safety because a proportion of passengers may be unable and/or may need assistance to leave the train in case of an emergency (Fridolf et al., 2012). A further study with more focus on this issue is therefore suggested.

Data provided in this study can help rail operators, fire safety engineers, designers and researchers to analyse the impact of different evacuation strategies in rail tunnels by considering flow merging processes. Due to evacuees are likely to leave a train through several exits, it is plausible to perform a controlled evacuation that gives priority to the passengers that are closer to fire to minimize the exposure time and reduces congestion. A similar conclusion has previously been presented in (Fridolf et al., 2014a; Oswald et al., 2008; 2011). Other strategies may involve closing certain exits to reduce the merging points while allowing quick and safe movement of passengers inside the train (Capote et al., 2012a) and help vulnerable passengers, when necessary i.e. the use of emergency ladders.

Although results of this study are promising, there are some limitations to bear in mind that should be addressed in future research. Despite the mock-up was flexible to manipulate the exit conditions, this may lead to a lack of realism. Care should be taken, however, in generalizing from this finding since other factors can impact on real evacuations (collective behaviours, passengers unable to negotiate the train exit, crew evacuation procedures, visibility conditions, presence of smoke, etc.). It is therefore necessary to complement the presented results in a real tunnel environment.

\section{Acknowledgments}

This research was supported by the Spanish Ministry of Economy and Competitiveness for the EVACTRAIN Project grant, Ref.: BIA2011-26738, co financed by ERD funds. The authors would like to acknowledge the participants for their involvement and patience. Without their cooperation this research would not have been possible.

\section{References}

Aghabayk, K., Ejtemai, O., Sarvi, M. and Sobhani, A. 2014. Understanding pedestrian crowd merging behavior. Transportation Research Procedia 2: 768 - 773 .

Alvear, D., Abreu, O., Cuesta, a. and Alonso, V., 2013. Decision support system for emergency management: Road tunnels. Tunnelling and Underground Space Technology, 34:13-21.

Boltes, M., Zhang, J., Seyfried, A., \& Steffen, B. 2011. T-junction: Experiments, trajectory collection, and analysis. In Computer Vision Workshops (ICCV Workshops), 2011 IEEE International Conference on (pp. 158-165). IEEE.

Boyce, K., Purser, D. and Shields, J. 2012. Experimental studies to investigate merging behaviour in a staircase. Fire and Materials 36: 383-398.

Brys, G., Hubert, M., Struyf, A. A robust measure of skewness. Journal of Computational and Graphical Statistics, 13:996-1017, 2004.

Capote, J., Alvear, D., Abreu, O. and Cuesta, A. 2012a. Analysis of evacuation procedures in high speed train fires. Fire Safety Journal 49: 35-46.

Capote, J., Alvear, D., Abreu, O., Cuesta, A. and Alonso, V. 2012b. A stochastic approach for simulation human Behavior during evacuation process in passenger trains. Fire 
Technology 48:911-925.

Craesmeyer, M. and Schadscheneider, A. 2014. Simulation of merging pedestrian streams at Tjunctions. Transportation research Procedia, 405:405-411.

Critical Values for the Two-sample Kolmogorov-Smirnov test (2-sided). http://www.soest.hawaii.edu/wessel/courses/gg313/

Cuesta, A., Alvear, D., Abreu, O. and Silió, D. 2014. Real-time stochastic evacuation models for decision support in actual emergencies. Fire Safety Science 11:1063-1076.

Cuesta, A., Abreu, O. and Alvear, D. 2016. Future challenges in evacuation modelling. Evacuation modeling trends. Springer International Publishing: 103-129.

Eisenhauer, J. G. Regression through the Origin. Teaching Statistics. Vol. 25, Issue 3: $76-80$, 2003.

European Commission, 2014. Commission Regulation (EU) No 1303/2014 of 18 November 2014. concerning the technical specification for interoperability relating to 'safety in railway tunnels' of the rail system of the European Union. Official Journal of the European Union.

Fay, M. P., Proschan, M. A., 2010. Wilcoxon-Mann-Whitney or t-test? On assumptions for hypothesis tests and multiple interpretations of decision rules. Statistics Surveys. 4: 1-39.

Scott, P. et al. Fire in Tunnels. Technical report part 2. Fire Safe Design-Rail Tunnels, European Thematic Network Fire in Tunnels.

Frantzich, H., Nilsson, D., 2004. Evacuation experiments in a smoke filled tunnel. In: proceedings of 3rd International Symposium Human Behaviour in Fire, pp. 229-238

Fridolf, K., Nilsson, D. and Frantzich, H. 2014a. The flow rate of people during train evacuation in rail tunnels: Effects of different train exit configurations. Safety Science 62: 515-529.

Fridolf, K., Andrée, K., Nilsson, D. and Frantzich, H. 2014b. The impact of smoke on walking speed. Fire and Materials 38:744-759.

Fridolf, K., Nilsson, D. and Frantzich, H. 2016. Evacuation of a metro train in an underground rail transportation system: flow rate capacity of train exits, tunnel walking speeds and exit choice. Fire Technology 52: 1481-1518.

Fridolf, K., Nilsson, D. and Frantzich, H. 2012. Train evacuation inside a tunnel: an interview with senior citizens and people with disabilities. In $5^{\text {th }}$ International Symposium on Human Behaviour in Fire, pp. 346-358.

Hamacher, et al. 2011 Simulation models of merging priorities in staircases, Pedestrian and Evacuation Dynamics, Springer, Berlin, pp. 925-933

Galea, E.R., Blackshields, D., Finney, K.M and Cooney, D.P. 2014. Passenger Train Emergency Systems: Development of Prototype railEXODUS Software for U.S. Passenger Rail Car Egress. Final Report. U.S. Department of Transportation Federal Railroad Administration.

Galea, et al. 2008. Investigating the representation of merging behavior at the floor stair interface in computer simulations of multi-floor building evacuations, J. Fire Protect. Eng., 18 (4), pp. 291-316.

Gwynne, S., Rosenbaum, E., 2015. Employing the hydraulic model in assessing emergency movement. In: DiNenno, P.J. (Ed.), The SFPE Handbook of Fire Protection Engineering, fourth ed. National Fire Protection Association, Quincy, MA, pp. 3-373-3-396.

Gwynne,S., Kuligowski, E., Kratchman, J. and Milke, J.A. 2009.Questioning the linear relationship between doorway width and achievable flow rate, Fire Safety Journal 4480 87.

Hokugo, A. Kubo, K and Murozaki, Y. 1985. An experimental study on confluence of two foot traffic flows in staircase, J. Archit. Plan. Environ. Eng., 358: 37-43. 
Hubert, M., Vandervieren, E., 2008. An adjusted boxplot for skewed distributions. Computational Statistics \& Data Analysis, V. 52, I. 12: 5186-5201.

Kim, J., et al. 2012. Experiments of egress behavior when subway car stops on track. 5th International Symposium on Human Behaviour in Fire, Cambridge, pp. 530-535.

Mann, H. B., Whitney, D. R. On a Test of Whether one of Two Random Variables is Stochastically Larger than the Other. Annals of Mathematical Statistics. 18 (1): 50-60,

Markos, S.H. and Pollard, J.K. 2013. Passenger Train Systems: Single-Level Commuter Rail Car Egress Experiments. Prepared by Volpe Center/USDOT for FRA/USDOT. Final Report. In FRA report approval process as of May 2013.

Maronna, R.A., Yohai, V.J. The behaviour of the Stahel-Donoho robust multivariate estimator. Journal of the American Statistical Association, 90:330-341, 1995.

Melly, M., Lennon, P. and Lennon, R. 2009. Who defers to whom? Deference behaviour on stairs. 4th International Symposium on Human Behaviour in Fire, Cambridge, pp. 135-146.

Nelson, E. and Mowrer, F. 2002. Emergency Movement. In: DiNenno, P.J. (Ed.), The SFPE Handbook of Fire Protection Engineering, third ed. National Fire Protection Association, Quincy, MA, pp. 3-367-3-380.

Norén, A., and Winér, J. 2003. Modelling Crowd Evacuation from Road and Train Tunnels-Data and design for faster evacuations. Report 5127, Department of Fire Safety Engineering Lund University, Sweden.

Oswald, M., Kirchberger, H., Lebeda, C., 2008. Evacuation of a high floor metro train in a tunnel situation: experimental findings. In: Klingsch, W.W., Rogsch, C., Schadschneider, A., Schreckenberg, M. (Eds.), Fourth International Conference on Pedestrian and Evacuation Dynamics, PED 2008. Springer, University of Wuppertal, Germany, pp. 67-81.

Oswald, M., Schjerve, N., Lebeda, C., 2011. Carriage evacuations in local, public rail transportation systems in case of fire experiments, findings and human behavior. In: Advanced Research Workshop on Evacuation and Human Behavior in Emergency Situations, Santander, Spain, pp: 309-336.

Pauls, J. L. 2004. Suggestions on evacuation models and research questions. In Conference Proceedings of the 3rd International Symposium on Human Behaviour in Fire.

Ronchi, E., Colonna, P., Capote, J., Alvear, D., Berloco, N., and Cuesta A., 2012. The evaluation of different evacuation models for assessing road tunnel safety analysis. Tunnelling and Underground Space Technology, 30:74-84.

Ruxton, G. D. The unequal variance t-test is an underused alternative to Student's t-test and the Mann-Whitney U test. Behavioural Ecology. 17: 688-690, 2006.

Sano, T., Ronchi, E., Minegishi, Y. and Nilsson, D. 2017. A pedestrian merging flow model for stair evacuation, 89:77-89.

Sano, T., Yajima, M., Kadokura, H. and Sekizawa, A. 2015. Characteristics of Evacuation Behavior Based on Observation of a Total Evacuation Drill in a High-rise Building, Interscience Communications, Cambridge, UK, pp. 97-108.

Seike, M., Kawabata, N., and Hasegawa, M. 2016. Experiments of evacuation speed in smokefilled tunnel. Tunnelling and Underground Space Technology, 53:61-67.

Shi, X., Ye, Z., Shiwatoki, K., Tang, D., Wang, C. and Wang, W. 2016. Empirical investigation on safety constraints of merging pedestrian crowd through macroscopic and microscopic analysis. Accident Analysis and Prevention 95: 405-416.

Shiwakoti, N., Gong, Y., Shi. X. and Ye, Z. 2015. Examining influence of merging architectural features on pedestrian crowd movement. Safety Science, 75:15-22.

Stephens, M. A. 1974. EDF Statistics for Goodness of Fit and Some Comparisons. Journal of the American Statistical Association. American Statistical Association. 69 (347): 730-737. 
Takeichi, N., Yoshida, Y. and Sano, T. 2005. Characteristics of Merging Occupants in a Staircase, Fire safety Science-Proceedings of the $9^{\text {th }}$ International Symposium, pp. 591-598

Train Door Emergency Egress and Access and Emergency Evacuation Procedures. 2004 Independent Transport Safety \& Reliability Regulator. Independent Transport Safety \& Reliability Regulator. Transport Safety Regulation Division. Document reference 02468, November 2004.

Tukey, J.W. 1977. Exploratory Data Analysis. Reading (Addison-Wesley), Massachusetts.

Wang, W.L. and Jacqueline Lo, T. Y. 2014. A Simulation Study on Passenger Escape in Rail Tunnels. Procedia Engineering 71:552-557.

Weyenberge, B.V. and Deckers, X. 2014. Development of a risk assessment method for fire in rail tunnels. 7th International Conference Tunnel Safety and Ventilation, Graz, pp. 180189.

Zhang, J. Klingsch, W., Schadschneider, A, and Seyfried, A. 2011. Transitions in pedestrian fundamental diagrams of straight corridors and T-junctions. Journal of Statistical Mechanics: Theory and Experiment, 2011(06), P06004.

Zhang, J. Klingsch, W., Schadschneider, A, and Seyfried, A. 2013. Experimental study of pedestrian flow through a T-junction. In Traffic and Granular Flow'11, pp. 241-249. 